\title{
European Society of Endocrinology Clinical Practice Guidelines for the management of aggressive pituitary tumours and carcinomas
}

\author{
Gerald Raverot ${ }^{1,2,3}$, Pia Burman ${ }^{4}$, Ann McCormack ${ }^{5,6}$, Anthony Heaney7, Stephan Petersenn ${ }^{8}$, Vera Popovic $^{9}$, \\ Jacqueline Trouillas ${ }^{2,10}$ and Olaf M Dekkers ${ }^{11,12}$ on behalf of The European Society of Endocrinology
}

${ }^{1}$ Fédération d'Endocrinologie, Centre de Référence des Maladies Rares Hypophysaires HYPO, Groupement Hospitalier Est, Hospices Civils de Lyon, Bron, France, 'Faculté de Médecine Lyon Est, Université Lyon 1, Lyon, France, ${ }^{3}$ INSERM U1052, CNRS UMR5286, Cancer Research Centre of Lyon, Lyon, France, ${ }^{4}$ Department of Endocrinology, Skane University Hospital Malmö, University of Lund, Lund, Sweden, ${ }^{5}$ Garvan Institute, Sydney, Australia, ${ }^{6}$ Department of Endocrinology, St Vincent's Hospital, University of New South Wales, Sydney, Australia, 7 Department of Medicine, David Geffen School of Medicine, University of California, Los Angeles, California, USA, ${ }^{8}$ ENDOC Center for Endocrine Tumors, Hamburg, Germany, ${ }^{9}$ Medical Faculty, University Belgrade, Belgrade, Serbia, ${ }^{10}$ Centre de Pathologie et de Biologie Est, Groupement Hospitalier Est, Hospices Civils de Lyon, Bron, France, ${ }^{11}$ Departments of Internal Medicine (Section Endocrinology) \& Clinical Epidemiology, Leiden University Medical Centre, Leiden, The Netherlands, and ${ }^{12}$ Department of Clinical Epidemiology, Aarhus University, Aarhus, Denmark

\begin{abstract}
Background: Pituitary tumours are common and easily treated by surgery or medical treatment in most cases. However, a small subset of pituitary tumours does not respond to standard medical treatment and presents with multiple local recurrences (aggressive pituitary tumours) and in rare occasion with metastases (pituitary carcinoma). The present European Society of Endocrinology (ESE) guideline aims to provide clinical guidance on diagnosis, treatment and follow-up in aggressive pituitary tumours and carcinomas.

Methods: We decided upfront, while acknowledging that literature on aggressive pituitary tumours and carcinomas is scarce, to systematically review the literature according to the GRADE (Grading of Recommendations Assessment, Development and Evaluation) system. The review focused primarily on first- and second-line treatment in aggressive pituitary tumours and carcinomas. We included 14 single-arm cohort studies (total number of patients $=116$ ) most on temozolomide treatment ( $n=11$ studies, total number of patients $=106$ ). A positive treatment effect was seen in $47 \%$ (95\% Cl: $36-58 \%)$ of temozolomide treated. Data from the recently performed ESE survey on aggressive pituitary tumours and carcinomas (165 patients) were also used as backbone for the guideline.

Selected recommendation: (i) Patients with aggressive pituitary tumours should be managed by a multidisciplinary expert team. (ii) Histopathological analyses including pituitary hormones and proliferative markers are needed for correct tumour classification. (iii) Temozolomide monotherapy is the first-line chemotherapy for aggressive pituitary tumours and pituitary carcinomas after failure of standard therapies; treatment evaluation after 3 cycles allows identification of responder and non-responder patients. (iv) In patients responding to first-line temozolomide, we suggest continuing treatment for at least 6 months in total. Furthermore, the guideline offers recommendations for patients who recurred after temozolomide treatment, for those who did not respond to temozolomide and for patients with systemic metastasis.
\end{abstract}




\section{Summary of the recommendations}

The recommendations (R) are worded as recommend (strong recommendation) and suggested (weak recommendation). We formally graded only the evidence underlying recommendations for therapeutic choices. The quality of evidence behind the recommendations is classified as very low $(+\mathrm{Ooo})$, low $(++\mathrm{Oo})$, moderate $(+++\mathrm{O})$ and strong (++++). See section 'Summary of methods used for guideline development'.

\section{General remarks}

R 1.1.1 We recommend that these patients should be discussed in a multidisciplinary expert team meeting (endocrinologist, neurosurgeon, pituitary pathologist, neuroradiologist, radiation oncologist, medical oncologist).

\section{Assessment of aggressiveness}

\subsection{Diagnosis of an aggressive pituitary tumour}

R 2.1.1 We recommend the diagnosis of an aggressive pituitary tumour be considered in patients with a radiologically invasive tumour and unusually rapid tumour growth rate, or clinically relevant tumour growth despite optimal standard therapies (surgery, radiotherapy and conventional medical treatments).

R 2.1.2 We recommend that imaging (MRI in most instances) should be used for quantification of tumour dimensions, invasion and growth.

R 2.1.3 We recommend full endocrine laboratory evaluation in patients with aggressive pituitary tumours.

R 2.1.4 In patients with aggressive pituitary tumours, and either site-specific symptoms or discordant biochemical and radiological findings, we recommend screening for metastatic disease.

\subsection{Potential predictors of aggressiveness in pitu- itary tumours}

R 2.2.1 We recommend that all pituitary tumours should undergo histopathological analysis, which should include a minimum immunodetection of pituitary hormones and Ki-67 proliferative index evaluation. The p53 immunodetection and the mitotic count should be evaluated at least, when the Ki-67 index is $\geq 3 \%(+000)$.

R 2.2.2 We suggest interpretation of histopathological results in the clinical context of the individual patient $(+000)$.
R 2.2.3 In patients with aggressive pituitary tumours, we suggest germline genetic testing based on young age at presentation or family history of pituitary or endocrine neoplasia, as recommended for patients with nonaggressive pituitary tumours $(+000)$.

\section{Therapeutic options}

\subsection{Role of surgery}

R 3.1.1 We recommend that surgery should be performed by a neurosurgeon with extensive experience in pituitary surgery $(++00)$.

R 3.1.2 We recommend discussion with an expert neurosurgeon regarding repeat surgery prior to consideration of other treatment options $(++00)$.

\subsection{Role of radiotherapy}

R 3.2.1 We recommend radiotherapy in patients with clinically relevant tumour growth despite surgery in nonfunctioning tumours or surgery and standard medical treatment in functioning tumours $(++00)$.

R 3.2.2 We suggest that adjuvant radiotherapy should be considered in the setting of a clinically relevant invasive tumour remnant with pathological markers (Ki67 index, mitotic count, p53 immunodetection) strongly indicating aggressive behaviour (+000).

R 3.2.3 We suggest discussion with an expert radiation oncologist regarding the different radiotherapeutic options taking into consideration tumour size and location, as well as pathology, prior RT and dose.

\subsection{Standard medical therapies}

R 3.3.1 We recommend standard medical treatment with maximally tolerated doses in order to control tumour growth, as per current guidelines.

\subsection{Medical therapies in aggressive pituitary tumours}

R 3.4.1 We recommend use of temozolomide monotherapy as first-line chemotherapy for aggressive pituitary tumours and pituitary carcinomas, following documented tumour growth $(++00)$.

R 3.4.2 We recommend first evaluation of treatment response after 3 cycles. If radiological progression is demonstrated, temozolomide treatment should be ceased $(++00)$. 
R 3.4.3 We recommend use of the standard dosing regimen: $150-200 \mathrm{mg} / \mathrm{m}^{2}$ for 5 consecutive days every 28 days $(+000)$.

R 3.4.4 We recommend monitoring of haematological parameters, liver function tests and careful clinical observation for potential adverse effects during treatment $(+++0)$.

R 3.4.5 We suggest, in patients with rapid tumour growth in whom maximal doses of radiotherapy have not been reached, combining temozolomide with radiotherapy (Stupp protocol) (+000).

R 3.4.6 We suggest that evaluation of MGMT status by immunohistochemistry by an expert neuropathologist should be performed. High MGMT expression is suggestive of a lack of response; however, there may be exceptions $(++00)$.

R 3.4.7 In patients responding to first-line temozolomide, as assessed after 3 cycles, we suggest treatment to be continued for at least 6 months in total, with consideration for longer duration if continued therapeutic benefit is observed (+000).

R 3.4.8 In patients with rapid tumour progression on temozolomide treatment, we suggest a trial with other systemic cytotoxic therapy. Given the variety of chemotherapeutic agents that have been reported, we cannot suggest a particular regimen $(+000)$.

R 3.4.9 In patients who develop a recurrence following response to temozolomide treatment, we suggest a second trial of 3 cycles of temozolomide $(+000)$.

\subsection{Local treatment of metastatic disease}

R 3.5.1 In patients with isolated metastases, we suggest consideration of loco-regional therapies, independent of decisions regarding the need for systemic treatment $(+000)$.

\section{Follow-up of an aggressive pituitary tumour}

R 4.1 We recommend that imaging (MRI in most instances) is performed every $3-12$ months as guided by prior tumour growth rate and/or location of tumour (proximity to vital structures) (+000).

R 4.2 We recommend that full endocrine evaluation should be performed every 3-12 months as guided by the clinical context $(+000)$.

R 4.3 We recommend lifelong follow-up of patients with aggressive pituitary tumours $(++00)$.

\section{Introduction}

The prevalence of clinically relevant pituitary tumours is 80-100 cases per 100000 with an annual incidence of 4 new cases per $100000(1,2,3)$. Incidence rates depend on age and sex (3). The clinical behaviour of pituitary tumours is highly variable: some remain quiescent for long periods of time; many grow slowly, while in rare cases rapid tumour growth is observed. Post-operatively, about $30 \%$ of the patients show tumour regrowth $0.4-37$ years after surgery, with an increased risk of tumour progression in the presence of residual tumour (4). A small subset of pituitary tumours has been classified as aggressive pituitary tumours, based on resistance to medical treatment and multiple recurrences despite standard therapies combining surgical, medical and radiotherapy treatment approaches. The prevalence of aggressive tumours is not known. Such tumours often, but not always, exhibit one of the 3 markers (Ki-67 $\geq 3 \%$, and/or increased mitoses, and/or p53 expression). Tumours exhibiting 2 or 3 markers were found to account from $2.5 \%$ to $10 \%$ in surgical series (5, $6,7,8)$. Pituitary carcinomas, defined by the presence of craniospinal and/or systemic metastasis, are rare, and reported to account for $0.2 \%$ of pituitary tumours $(9,10)$.

Early identification of aggressive pituitary tumours is challenging, but is of major clinical importance as they are associated with an increased morbidity and mortality even in the absence of metastases $(11,12)$. Despite numerous studies and advances in prognostic classification, no pathological marker has been shown as yet to reliably predict pituitary tumour behaviour $(6,13,14,15)$. This guideline proposes a definition of an aggressive pituitary tumour and provides recommendations for current management.

\section{Methods}

\subsection{Guideline working group}

This guideline was initiated by The European Society of Endocrinology (ESE). The chair (G R) and members of the working group (authors) were appointed by the chair and approved by the ESE Clinical Committee: endocrinologists (P B, A P H, A M C, S P, V P), pathologist $(\mathrm{J} T)$ and a methodologist $(\mathrm{O} \mathrm{D})$. The working group had three in-person meetings between May 2016 and April 2017. Additional communication occurred by teleconference and email and prior to the process, all participants completed conflict of interest forms. 
Prior to publication, a draft of the guideline was reviewed by 8 experts in the field (see 'Acknowledgement' section). Revision of the guidelines was based on feedback from ESE Members, the ESE Council of Affiliated Societies (ECAS) and following presentation at the ECE 2017. All comments and suggestions were discussed and implemented as appropriate by the working/writing group.

\subsection{Target group}

In line with previous ESE guidelines, this document was developed for healthcare providers of patients with aggressive pituitary tumours but can also provide guidance as patient information material.

\subsection{Aims}

The overall purpose of this guideline is to provide clinicians with practical guidance for identification and management of patients with aggressive pituitary tumours. It was prompted by the increasing use of temozolomide (TMZ) in aggressive pituitary tumours.

\subsection{Summary of methods used for guideline development}

The methods used have been described in more detail previously $(16,17)$. In short, the guideline used GRADE (Grading of Recommendations Assessment, Development and Evaluation) as a methodological base. The first step was to define the clinical questions (see 'Clinical questions and eligibility criteria' section), the second being a systematic literature search (see 'Description of search and selection of literature' section). After including relevant articles, we (1) estimated an average effect for specific outcomes (if possible), and (2) rated the quality of the evidence. The quality of evidence behind the recommendations is classified as very low $(+000)$, low $(++00)$, moderate $(+++0)$ and strong $(++++)$.

For the recommendations, we took into account: (1) quality of the evidence, (2) balance of desirable and undesirable outcomes and (3) values and preferences (patient preferences, goals for health, costs, management inconvenience, feasibility of implementation, etc.) $(16,17)$. The recommendations are worded as recommend (strong recommendation) and suggest (weak recommendation). Formal evidence syntheses were performed and graded only for recommendations addressing our initial questions. It is important to emphasise that there is no direct translation from the (quality) of evidence to the strength of a recommendation. Furthermore, there might be situations when a recommendation is strong even if the quality of evidence is low (18). Moreover, a guideline panel should carefully consider whether to abstain from recommendations in the absence of good quality evidence, as the main disadvantage of abstaining is that it suggests that all alternatives then seem equally (un)reasonable (17). This will often not be the case. Recommendations based on good practice were not graded. Recommendations were derived from a majority consensus of the guideline development committee, but substantive disagreements could be acknowledged in the manuscript. For transparency, all recommendations provided are accompanied by text explaining why specific recommendations were made.

\subsection{Clinical questions and eligibility criteria}

Prior to formulating recommendations, the working group decided to perform a systematic review regarding efficacy of different treatment regimens in aggressive pituitary tumours. As we did not expect to find many large comparative studies, we decided that single-arm cohort studies were eligible. A minimum of 3 patients were required for eligibility to avoid selection bias.

In addition, an extensive search was performed to provide an overview of publications including case reports on even less well-documented subject areas such as surgery and/or radiotherapy.

\subsection{Description of search and selection of literature}

A literature search in electronic medical databases was performed with the help of a trained librarian. The search revealed 811 titles. Ultimately, we included 14 studies reporting therapy in aggressive pituitary tumours with $\geq 3$ patients: 11 examined the effect of TMZ therapy alone (Supplementary Table 1 , see section on supplementary data given at the end of this article), 1 examined the combined effect of chemotherapy and TMZ (Supplementary Table 2), and two studies on peptide radio-receptor therapy (PRRT) (Supplementary Table 3).

\subsection{Summary and conclusions from the systematic review}

In the 11 studies on TMZ therapy in aggressive pituitary tumours, patient numbers ranged from 3 to 31, with only four studies having $>10$ patients. There were substantial differences between studies with respect to follow-up 
duration and TMZ schedule; many studies did not provide a definition of response. Overall, the quality of the evidence was considered very low (+000). (Supplementary Tables 1, 2 and 3). In published literature, the pooled proportion of patients with a tumour response after TMZ was estimated to be 47\% (95\% CI 36-58\%) (Supplementary Table 4) (Fig. 1).

\section{Recommendations, rationale for the recommendations}

\section{General remarks}

The diagnosis, management and treatment of aggressive pituitary tumours and pituitary carcinomas remain a challenge.

R 1.1.1 We recommend that these patients should be discussed in a multidisciplinary expert team meeting (endocrinologist, neurosurgeon, pituitary pathologist, neuroradiologist, radiation oncologist, medical oncologist).

\section{Assessment of aggressiveness}

\subsection{Diagnosis of an aggressive pituitary tumour}

R 2.1.1 We recommend that the diagnosis of an aggressive pituitary tumour should be considered in patients with a radiologically invasive tumour and unusually rapid

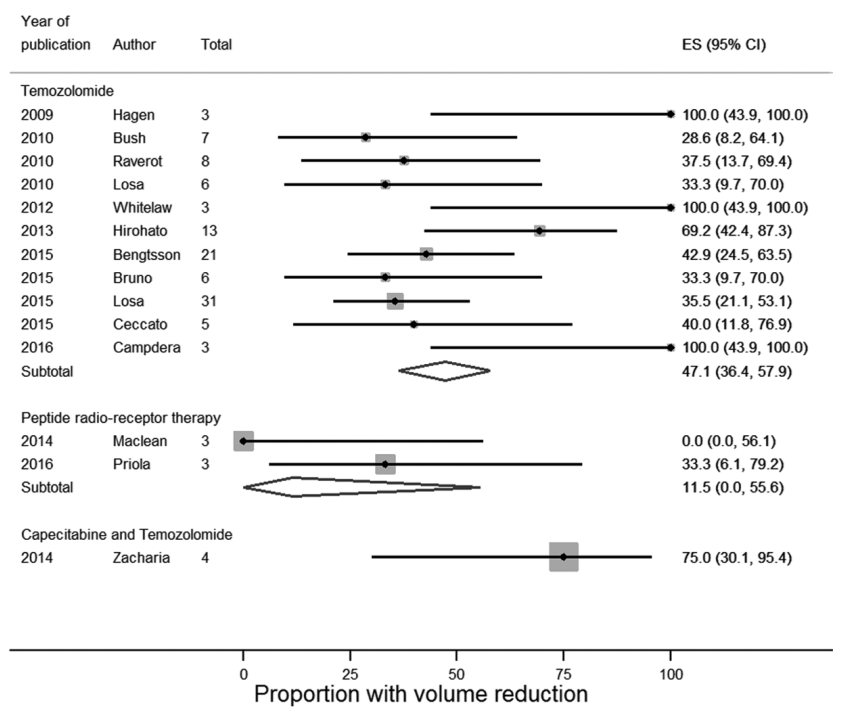

\section{Figure 1}

Meta-analysis of treatment effect in aggressive pituitary tumours and carcinomas. tumour growth rate, or clinically relevant tumour growth despite optimal standard therapies (surgery, radiotherapy and conventional medical treatments).

\section{Reasoning}

The hallmark of aggressiveness is clinically relevant tumour growth despite the use of optimal standard therapies, which entails a combination of medical therapies, surgery and radiotherapy as proposed in clinical management guidelines (Supplementary Table 5). Standard medical therapies and resistance to such treatment are discussed in more detail in Section 3.3. With regard to surgical management, it is important to distinguish between recurrence following non-optimal surgery and recurrence after surgery performed by an expert. The growth rate of pituitary tumours is influenced by patient- and tumourspecific characteristics; this intrinsic tumour heterogeneity determines the risk of recurrence and resistance to treatment $(6,19,20)$.

Invasiveness alone is not synonymous with pituitary tumour aggressiveness (21); however, invasion is a major determinant of incomplete tumour resection. Aggressive pituitary tumours are almost always macroadenomas at clinical presentation. However, pituitary tumour size at presentation does not equate to potential for aggressive behaviour, as illustrated by giant lactotroph tumours that may be very sensitive to dopamine agonist treatment $(22,23)$.

The time interval between the primary diagnosis and the aggressive tumour behaviour varies from months to $>10$ years. There may be extended periods of clinical quiescence for several years followed by a period of rapid tumour growth, invasion or metastasis $(24,25,26,27)$.

R 2.1.2 We recommend that imaging (MRI in most instances) should be used for quantification of tumour dimensions, invasion and growth.

\section{Reasoning}

An imaging study (preferably MRI or CT where bone invasion assessment is indicated) that enables accurate and consistent measurement of tumour sites, dimensions and invasion is recommended. The imaging protocol should comprise thin $(2-3 \mathrm{~mm})$ sagittal $\mathrm{T} 1$, coronal $\mathrm{T} 1$ before and after gadolinium injection, coronal $\mathrm{T} 2$ or axial T1-weighted slices. Comparison with penultimate and prior remote imaging studies is essential to identify tumour progression and to guide appropriate treatment (28). 
R 2.1.3 We recommend full endocrine evaluation in patients with aggressive pituitary tumours.

\section{Reasoning}

Assessment of pituitary endocrine function is essential at presentation to identify secretory tumours that may indicate specific therapies or endocrine deficiencies, which if left untreated would contribute to patient morbidity. Assessment of pituitary endocrine function should be performed, at appropriate intervals (3-6 months on an individualised basis), both to characterise potential biomarkers of disease progression to monitor in parallel with imaging studies, and to manage endocrine deficiencies.

R 2.1.4 In patients with aggressive pituitary tumours, and either site-specific symptoms or discordant biochemical and radiological findings, we recommend screening for metastatic disease.

\section{Reasoning}

Given that aggressive pituitary tumours often progress and occasionally metastasize insidiously over several years, attention should be paid and appropriate structural (MRI and CT) and/or functional (FDG- and/or SSTR-PET) imaging studies should be considered, in the setting of site-specific symptoms (neck/back pain or neurological complaints), and/or where laboratory measures are discordant with known visible extent of disease (increase in hormone levels without corresponding increase in tumour size). Common sites for metastatic disease include craniospinal deposits, neck lymphatic chains and less commonly liver, bone and lung.

\subsection{Potential predictors of aggressiveness in pitu- itary tumours}

R 2.2.1 We recommend that all pituitary tumours should undergo histopathological analysis, which should include a minimum immunodetection of pituitary hormones and Ki-67 proliferative index evaluation. The p53 immunodetection and the mitotic count should be evaluated at least, when the Ki-67 index is $\geq 3 \%$ (+000).

\section{Reasoning}

Based on immunohistochemistry (IHC), pituitary tumours are classified into somatotroph (GH, Pit 1 positive), lactotroph (PRL, Pit1 and ER positive), corticotroph
(ACTH, Tpit positive), thyrotroph (TSH, Pit1 positive), gonadotroph (FSH/LH, SF1 positive), null cell (negative for hormones and transcription factors) tumours and plurihormonal and double tumours (29). Transcription factors staining could be helpful for immunonegative tumours but not for the assessment of aggressiveness.

The use of proliferative markers as prognostic tools in the assessment of a pituitary tumour is controversial. Nevertheless, some criteria (Ki-67 >3\%, extensive p53 immunoreactivity and increased mitotic activity) were incorporated into the 2004 WHO Classification (30). However, there are difficulties with the interpretation of this classification, and it has never been validated in a clinical context. There remains no clear consensus on the Ki-67 index that may identify tumours at a high risk of recurrence, with widely different cut-offs proposed, ranging from $1.3 \%$ (5) to 10\% (31), sometimes adapted to the tumour subtype (32). However, a cut-off $\geq 3 \%$ is mostly used. Most studies are based on a limited number of cases, short follow-up or expert opinion only. Some authors consider that a Ki-67 $>10 \%$ is a sign of malignancy (31), again without prospective validation.

Mitotic count has been recently re-evaluated and mitotic count $>2$ is suggestive of risk of recurrence (13). The prognostic value of p53 is also debated because a reliable method of quantification has not been validated (33). However, a common definition of positive staining (>10 strongly positive nuclei per $10 \mathrm{HPFs}$ ) has been agreed upon $(6,13,34,35)$.

The combination of invasion (determined radiologically) and use of proliferative markers (Ki-67 index $\geq 3 \%$ and mitotic count $>2$ ) and p53 (assessed by IHC pathologically) has been proposed to be superior in identifying pituitary tumours with a higher risk of progression/recurrence $(6,36)$.

We acknowledge that no marker alone is sufficient to predict tumour behaviour. However, in the recent ESE survey at least one pathology marker was available for 97 aggressive pituitary tumours and 34 carcinomas (unpublished ESE survey). Ki-67 $\geq 3 \%$ was the most frequent positive marker in aggressive pituitary tumours (79/97, 81\%) and carcinomas (29/34, 85\%); also p53 positivity (35/48; 73\% and $18 / 23 ; 78 \%$, respectively) and a mitotic count $>2$ mitoses/10HPFs were also frequently observed (26/41, 63\% and 18/20, 90\%, respectively, $P=0.03)$. The frequency of these markers was not different between aggressive pituitary tumours and carcinomas, but higher than observed in surgical series $(6,36)$.

Based on these results, and the last WHO classification on pituitary tumour (29), we recommend the evaluation 
of Ki-67 index at minimum, the p53 immunodetection and the mitotic count when the Ki- 67 index is $\geq 3 \%$.

R 2.2.2 We suggest interpretation of histopathological results in the clinical context of the individual patient $(+000)$.

\section{Reasoning}

In a study by Trouillas et al., invasive and proliferative (Ki-67 >3\% and p53 positive or number of mitosis $>2$ ) tumours (grade 2b) demonstrated a poorer prognosis with an increased probability (12 fold) of tumour progression/recurrence compared to non-invasive and non-proliferative tumours (grade 1a) (6).

It is also recognised that lactotroph tumours in men $(37,38)$ and silent corticotroph (ACTH positive) tumours demonstrate a more aggressive course, and may recur earlier than silent gonadotroph tumours (39, 40, 41). Rarely, initially silent corticotroph tumours may evolve to secrete ACTH after many years of follow-up, and this transformation may also herald more aggressive tumour behaviour $(42,43,44,45)$. Silent subtype III or plurihormonal silent tumours (40) also may exhibit a more aggressive clinical course compared with silent gonadotroph tumours (46).

R 2.2.3 In patients with aggressive pituitary tumours, we suggest germline genetic testing based on young age at presentation or family history of pituitary or endocrine neoplasia, as recommended for patients with non-aggressive pituitary tumours (+000).

\section{Reasoning}

Current suggestions on genetic testing in patients with pituitary tumours do not elaborate specifically on aggressive tumours $(15,47,48)$. In the absence of sufficient data in this regard, we suggest that indications for genetic testing should be applied as for non-aggressive pituitary tumours.

Some studies have suggested that more aggressive pituitary tumours may be found in association with MEN1 and AIP patients. Comparison of MEN1-positive pituitary tumours with an unselected group of non-MEN1 sporadic pituitary adenomas revealed that MEN1 tumours were larger and more often histologically invasive (49). In another study, young patients with pituitary tumours (mostly somatotroph tumours) were found to be more likely to carry AIP mutations among apparently sporadic populations (48). Other genes implicated in pituitary tumour predisposition include GPR101 (XLAG), p27Kip1 (multiple endocrine neoplasia type 4 (MEN4)), PRKAR1A (Carney complex), GNAS (McCune-Albright syndrome), neurofibromatosis type 1 , SDHx mutations and DICER1 syndrome (50). However, currently little is known about the potential for more aggressive pituitary tumour behaviour under these conditions.

\section{Therapeutic options}

\subsection{Role of surgery}

R 3.1.1 We recommend that surgery should be performed by a neurosurgeon with extensive experience in pituitary surgery $(++00)$.

\section{Reasoning}

Surgical approaches to either obtain complete neartotal resection or clinically relevant debulking should be balanced with safety considerations. Multiple studies have demonstrated that lower morbidity and mortality correlate with surgeon experience (51). Some studies suggest that the wider exposure and the enhanced direct visualisation attainable with endoscopic approaches may facilitate a more extensive surgical resection of these aggressive tumours that often extend beyond the sella into the cavernous sinuses and other parasellar structures. In other instances, a transcranial approach may offer advantages in resection of tumours that extend significantly into the suprasellar region.

R. 3.1.2 We recommend discussion with an expert neurosurgeon regarding repeat surgery prior to consideration of other treatment options.

\section{Reasoning}

Even in the setting of a patient with multiple prior surgeries and where significant tumour debulking is not attainable, surgery may still have a role to ameliorate local mass effects such as acute chiasmal compression, acute loss of vision or severe intractable headache or to offer control of hormone hypersecretion. Therefore, we recommend that at intervals, as directed by individual patient needs, further surgical intervention should be discussed within a multidisciplinary framework by the endocrinologist, neurosurgeon, neuroradiologist, radiation oncologist and medical oncologist to formulate the best patient care plan (52). 


\subsection{Role of radiotherapy}

R 3.2.1 We recommend radiotherapy in patients with clinically relevant tumour growth despite surgery in nonfunctioning tumours or surgery and standard medical treatment in functioning tumours $(++00)$.

\section{Reasoning}

Radiation therapy may offer the possibility of longterm control of tumour growth and should therefore be discussed in all patients with an aggressive pituitary tumour. Both fractionated external beam radiation therapy (EBRT) and stereotactic radiosurgery (SRS) are highly effective in pituitary tumours, although little data are available in more aggressive phenotypes. EBRT is usually delivered in 25-30 fractions with a total dose of 45-54 Gy. SRS can be delivered as a single-dose (typical dose: 12-14Gy, max. 16Gy). Fractionated SRS (usually $25 \mathrm{~Gy}$ in 5 fractions) is usually suggested in cases where a single-dose SRS endangers the optic pathway (53).

Comparison of the reported success rates is hindered by varying techniques and doses used for radiation therapy, as well as by different imaging protocols to assess tumour volume (54). Favourable outcome with SRS is more frequent in patients $>50$ years in age, in tumours $<5$ cc in volume, and in patients without prior radiation $(55,56)$. In pituitary tumour growth despite prior radiotherapy, both the target region and the doses applied during the first radiotherapy course should be discussed with an expert radiation oncologist to investigate whether additional doses to the region of current growth may be indicated.

The indication for radiotherapy must be balanced against potential side effects. In regular tumours, it is advisable to be very restrictive with RT, but in aggressive tumours, the balance between benefit and risks is very different although the side effects are similar. The most frequent long-term side effect of radiotherapy is hypopituitarism, affecting single or multiple pituitary axes. This probably occurs in almost all patients, when followed for a sufficiently long time, indicating the need for patient education and lifelong evaluation for pituitary insufficiency at regular intervals. Hypopituitarism itself may be a risk factor for premature mortality, other potential radiotherapy-related causes being vascular injury and haemodynamic changes (57). Furthermore, radiotherapy is associated with an increased risk of malignant brain tumours $(\mathrm{RR}=3.3)$ or meningioma $(\mathrm{RR}=4.1)$, and higher $(R R=14.1$ and 7.6, respectively), in patients treated with RT before the age 30 years (58). In previous smaller studies, the absolute risk was estimated to be $1-3 \%$ over 15-20 years, increasing to approximately 5\% after 30 years $(59,60)$. The risk of optic pathway injury is low with EBRT, with an estimate of $1 \%$ at 10 years and $1.5 \%$ at 20 years (61). For SRS, most series report neurological deficit rates of $<5 \%$, most commonly optic neuropathy (54). The maximum dose to the optic nerve system should be kept below the threshold of 8-12Gy to avoid injury to the visual system.

R 3.2.2 We suggest that adjuvant radiotherapy should be considered in the setting of a clinically relevant invasive tumour remnant with pathological markers (Ki67 index, mitotic count, p53 immunodetection) strongly indicating aggressive behaviour (+000).

\section{Reasoning}

While radiation therapy is widely considered to reduce the risk of recurrence, the true effect is difficult to quantify due to the lack of randomised studies. Results need to be compared to the natural history of tumour progression after incomplete resection, which is estimated to be $\leq 5 \%$ at 5 years and $10-25 \%$ at 10 years for gross totally resected tumours (61). One study compared post-operative results for patients with NFA from two centres, one of them routinely performing radiation therapy, the other rarely adopting this approach. Progression-free survival rates for patients with RT were 93\% at 5, 10 and 15 years, compared to 68,47 and $33 \%$, respectively, in patients without RT (62). The indication of radiotherapy should be discussed in patients with a tumour of high risk of recurrence and/or progression, as has been described in 'Potential predictors of aggressiveness in pituitary tumours' section.

R 3.2.3 We suggest discussion with an expert radiation oncologist regarding the different radiotherapeutic options taking into consideration tumour size, location, prior RT and dose as well as pathology.

\section{Reasoning}

For final evaluation and confirmation of doses to be delivered, thereby determining potential side effects, an experienced radiation oncologist is required (61). For SRS, the tumour target should be at least $3-5 \mathrm{~mm}$ distant from the optic chiasm and less than $3 \mathrm{~cm}$ in diameter. Otherwise, fractionated EBRT may be the only option. Furthermore, EBRT should be preferred for tumours with irregular anatomy, including diffuse local infiltration and suprasellar or brainstem extension, to avoid high dose radiation of healthy tissue (54). SRS may 
be more convenient for the patient with single session therapy compared to daily application of EBRT over several weeks. Importantly, there are no controlled trials comparing fractionated EBRT and SRS. Of note, SRS has been used as salvage therapy with some success in a small series of patients with persistent active tumour despite prior fractionated EBRT (63). Stereotactic guidance by high-resolution imaging allows very precise delivery of radiation to the tumour and is also increasingly used with EBRT. There are different modalities available to deliver radiation therapy, including linear accelerators (e.g. LINAC and more recently Cyber-knife, a frameless system using robotic mounting and real-time image guidance), multisource Cobalt 60 units (e.g. Gamma Knife) and particle beam accelerators (with limited availability due to the high costs). While there may be some theoretical advantages in using one modality over the other, the decision often lies with the availability of a system at the treating centre.

\subsection{Standard medical therapies}

R 3.3.1 We recommend standard medical treatment with maximally tolerated doses in order to control tumour growth, as per current guidelines (++00).

\section{Reasoning \\ Prolactinoma}

Cabergoline is the most effective and best tolerated drug for treating prolactinomas (64) (Supplementary Table 5). In most prolactinomas, normoprolactinemia and a reduction of tumour volume can be achieved with a dose $\leq 2 \mathrm{mg}$ /week (65). Male gender, invasive growth and giant tumours (i.e. diameter $>4 \mathrm{~cm}$ ) are associated with a lower response $(66,67)$. These tumours can often be controlled by increasing the weekly dose of cabergoline, by $0.5 \mathrm{mg}$ every 1-3 months, up to $3.5 \mathrm{mg}$ (66). However, some large tumours may be exquisitely sensitive to dopamine agonists. Some prolactinomas respond slowly and can eventually be managed using the same dose of cabergoline. In a subset of patients, prolactin levels may be normalised without a decrease in tumour size; the mechanism for this phenomenon remains to be clarified (65).

\section{Acromegaly}

Somatotroph tumours express somatostatin receptors (sst), predominantly sst2 and sst5 and less abundantly sst1 and sst3 (68). First (lanreotide, octreotide) and second generations (pasireotide) of somatostatin analogues are available (Supplementary Table 5) for treating acromegaly. In a recent study in treatment of naive patients, the PRIMARYS study (Lanreotide Autogel), normalisation of IGF-I combined with GH levels $<2.5 \mu \mathrm{g} / \mathrm{L}$ was achieved in $27 / 63(43.5 \%)$ of the patients (69). In a larger study of 358 medically naive patients, octreotide LAR was compared to pasireotide LAR, a multi-sst ligand acting on sst $1-3$ and particularly sst5. Normal IGF-I combined with GH levels $<2.5 \mu \mathrm{g} / \mathrm{L}$ was achieved in $19 \%$ of the patients given octreotide LAR vs 31\% given pasireotide LAR (70). Treatment with somatostatin analogues leads to tumour volume reduction by $>25 \%$ in $20 \%$ of the patients $(71,72)$. A higher proportion, $63 \%$ of 89 patients with macroadenomas (95\% CI 52.0-72.9), achieved $\geq 20 \%$ tumour volume reduction in the PRIMARYS study, the maximal decrease occurring within the first six months (69). Similar responses have been reported using octreotide $(70,73)$. An increase in tumour volume while on treatment with somatostatin analogues has been observed in $1-2 \%$ patients $(71,72)$, and is related to more aggressive tumour behaviour (74).

Pegvisomant, a GH receptor antagonist, is reported to normalise IGF-I in $63 \%$ (75) and $93 \%$ of the patients (76) depending on the clinical setting, whereas the effect on tumour size appears neutral. In the setting of a pituitary tumour partially controlled by somatostatin analogues, combination with pegvisomant could lead to IGF-I normalisation in most patients (77). Despite a potential benefit of dopamine agonist therapy alone or in addition to somatostatin analogue or pegvisomant (78), there are no prospective studies demonstrating its action on tumour growth in unselected or naive patients.

\section{Cushing's disease}

Corticotroph tumours express sst5 receptors, and less frequently sstr2 and dopamine receptors (Supplementary Table 5). Pasireotide is presently the only drug targeting the pituitary that is approved for treatment of Cushing's disease. In a study on 162 patients, pasireotide led to normalisation of UFC in $26 \%$ of the patients. There are limited data regarding the effect on tumour size (79). Dopamine agonists have not been confirmed to have any effect on corticotroph tumour growth (80).

\section{Thyrotroph tumours}

Related to the high expression of SSTR2 in these tumours (81), more than $90 \%$ of thyrotroph tumours respond to 
somatostatin analogues with restoration of a euthyroid state in $73-100 \%$ of cases, and a reduction in tumour size in $20-70 \%(82,83)$ (Supplementary Table 5). The response to dopamine agonists with regard to TSH secretion and tumour shrinkage has been variable, with best results in mixed thyrotroph/lactotroph tumours $(82,83)$.

\section{Resistance to standard medical treatment}

\section{Dopamine agonists}

Complete resistance to dopamine agonists, defined as failure to normalise prolactin and a less than 50\% decrease in size on doses of cabergoline up to $3.5 \mathrm{mg} /$ week, represents less than $10 \%$ of macroprolactinomas (66). Dopamine-resistant lactotroph tumours often are invasive macroadenomas, and according to some studies are more angiogenic and more proliferative (84). The resistant tumours often express a lower number of dopamine $\mathrm{D}_{2}$ receptors and ER receptors (38); other mechanisms have been proposed (85).

Furthermore, high doses, up to $11 \mathrm{mg} /$ week, have been shown to result in prolactin normalisation in most patients (86) (Supplementary Table 5). It is proposed that the highest tolerated dose of dopamine agonist should be used in patients with aggressive prolactinomas.

\section{Somatostatin analogues}

In acromegaly, treatment resistance, defined as a complete lack of biochemical and tumour response, occurs in less than $10 \%$ of the patients. The molecular basis is poorly understood. Several mechanisms have been proposed, such as defective expression or genetic alterations of somatostatin receptors (sst) and impaired signal transduction (87). A correlation has been demonstrated among sst2 mRNA, protein expression and the GH-lowering response to octreotide $(88,89)$. However, marked case-to-case variations among individual tumours have been found, and some tumours with high sst 2 may show a poor response to SSA (90). Pituitary somatotroph adenomas from AIP mutation carriers are less responsive to sst 2 analogues and recent data suggest that membranous sst2a are downregulated, whereas the expression of sst5 and the response to pasireotide are similar in AIP-sufficient and AIP-deficient tumours (91).

\subsection{Medical therapies in aggressive pituitary tumours}

Aggressive pituitary tumours usually respond poorly to the standard medical treatments used for non-aggressive tumours. However, in single patients with metastatic disease, non-cytotoxic drugs have been reported to, at least temporarily, reduce tumour burden, bromocriptine in two lactotroph tumours (92) and a high dose of octreotide in a malignant thyrotroph tumour (93). Standard medical treatments do not arrest growth of aggressive gonadotroph/NFPA tumours.

Morbidity and mortality in patients with aggressive corticotroph tumours are mostly related to cortisol excess. Drugs reducing adrenal glucocorticoid synthesis should be given in doses aiming at achieving eucortisolism. There is little experience with pasireotide in aggressive corticotroph tumours. A single patient with a large corticotroph tumour following bilateral adrenalectomy had a lowering of ACTH and sustained reduction of the suprasellar tumour (94). In another eight patients with Nelson's syndrome, pasireotide had minimal effects on tumour volume, in spite of reductions in ACTH levels in most patients (Daniel et al., abstract Endo 2016, OR 18-5). In a recent report on three patients with aggressive atypical corticotroph macroadenomas, of which one was a carcinoma, pasireotide was not clinically useful (95), and in three patients with recurrent corticotroph tumour after discontinuation of TMZ, pasireotide had no effect (12). There are several reports of corticotroph tumour growth after bilateral adrenalectomy, as well after achieving eucortisolism after treatment with steroidogenic inhibitors (96). This risk seems higher in patients with macroadenomas and aggressive corticotroph tumours (97, 98). To what extent bilateral adrenalectomy might trigger aggressive behaviour remains unknown. The biology of the corticotroph tumour per se might be the major determinant of continued progressive growth. There is not sufficient evidence to recommend or recommend against bilateral adrenalectomy in patients with aggressive corticotroph tumours in whom cortisol excess cannot be controlled by pharmacotherapy, surgery and radiotherapy.

\section{Chemotherapies}

R 3.4.1 We recommend use of temozolomide monotherapy as first-line chemotherapy for aggressive pituitary tumours and pituitary carcinomas, following documented tumour growth (++00).

\section{Reasoning}

The first use of temozolomide (TMZ) in the treatment of aggressive pituitary tumours was described in four cases in $2006(99,100,101)$. These reports were rapidly 
followed by a number of case reports in which most patients responded with a regression of tumour burden. This marked effect, however, could reflect publication bias. Eleven studies with at least 3 patients each have been published during 2010-2016 (Supplementary Table 1). These studies included a total of 106 patients, of whom 34 had carcinomas, treatment schedules mostly being TMZ $150-200 \mathrm{mg} / \mathrm{m}^{2} /$ day 5 days every 4 weeks. Two studies used a slightly different schedule $(102,103)$. The duration of treatment was often not specified. Despite a heterogeneous mix of patients, and differences in treatment schedules and imaging procedures, the response rate (defined as percentage of patients with a partial or complete tumour regression) has been broadly similar across the studies, with a reported volume reduction in $47 \%$ (95\% CI 36-58). A comparable efficacy, 37\%, was observed in 156 evaluable patients reported to the large ESE survey on aggressive pituitary tumours (unpublished ESE survey). Clinically functional tumours responded better than non-functioning. Published data indicate that the response to TMZ in patients with primary aggressive corticotroph tumours and patients with Nelson's syndrome is comparable. Overall, complete tumour regression has been seen in 13 patients, 5 carcinomas and 8 aggressive tumours, representing about $5 \%$ of all patients treated $(25,103,104,105,106$, unpublished ESE survey: personal communication ).

It should be noted that there are no head-to-head studies comparing temozolomide to other treatment options. However, given the course of the condition (spontaneous regression is not likely to occur), the panel felt reasonably comfortable to recommend the use of temozolomide given that the literature suggests a positive effect in a significant percentage of patients treated. This has not been shown for other treatment options.

\section{Combination of TMZ with other drugs}

A study using treatment with capecitabine before TMZ (CAPTEM) found a partial response of long duration in 4 out of 4 corticotroph tumours, of which one was a carcinoma (105). In studies with NET cell lines, the authors had observed a synergistic apoptosis when TMZ had been given after pretreatment with capecitabine compared with TMZ alone. Methylguanine methyltransferase (MGMT) levels were measured in 3 of the 4 patients, and were low in these three patients, which possibly contributed to the outcome (see 'Predictors of response to temozolomide' section). Others have added capecitabine to TMZ after TMZ failure, or at progression after an initial response to
TMZ alone, but had not observed an enhanced effect (11, $12,25,107)$.

In the ESE survey, combination chemotherapy with TMZ as first-line treatment was reported in 6 cases: capecitabine (in 3), bevacizumab (1), thalidomide (1) and BCNU (1) (unpublished ESE survey). Two of the 6 cases (one with bevacizumab and one with capecitabine) achieved a partial response, two demonstrated stable disease (capecitabine, thalidomide), and other two had progressive disease (capecitabine, $\mathrm{BCNU}$ ). At this stage, improved efficacy with TMZ in combination with other chemotherapy has not been demonstrated.

Pasireotide and octreotide have been used in combination with TMZ in a few patients with aggressive tumours $(102,108,109)$. The contribution of the somatostatin analogues to the treatment effects could not be determined, given the small numbers examined.

R 3.4.2 We recommend first evaluation of treatment response after 3 cycles. If radiological progression is demonstrated, temozolomide treatment should be ceased $(++00)$.

\section{Reasoning}

In general, an effect of TMZ is observed within 3-6 months, with parallel decreases in circulating hormone concentrations and tumour volumes $(25,107)$.

R 3.4.3 We recommend use of standard dosing regimen: $150-200 \mathrm{mg} / \mathrm{m}^{2}$ for 5 consecutive days every 28 days $(+000)$.

\section{Reasoning}

In most reports on aggressive pituitary tumours/ carcinomas, TMZ has been administered in cycles, 150$200 \mathrm{mg} / \mathrm{m}^{2}$ for 5 consecutive days every 28 days, here referred to as 'standard therapy regimen'. In the first cycle, $150 \mathrm{mg} / \mathrm{m}^{2} /$ day is used, with an increase to $200 \mathrm{mg} / \mathrm{m}^{2} /$ day in subsequent cycles if there is no toxicity. In patients with glioblastomas, TMZ is first given at a daily dose of $75 \mathrm{mg} / \mathrm{m}^{2}$ for 6 weeks in combination with radiotherapy, followed by $6-12$ months of 'standard therapy', referred to as 'the Stupp protocol'. Continuous dosing, $50 \mathrm{mg} /$ $\mathrm{m}^{2}$, or dose-dense regimens, with $50 \mathrm{mg} / \mathrm{m}^{2} 7 / 14$ days, or $21 / 28$ days, have been tried both in aggressive pituitary tumours and other malignancies with the hypothesis that larger doses over longer time would eventually deplete MGMT stores, and thereby increase the efficacy of TMZ therapy. However, in naive glioblastomas, dose-dense schedules had similar efficacy as the standard regimen, 
but with more side effects, particularly severe neutropenia (110). There are no studies comparing different dosing schedules in patients with aggressive pituitary tumours. In the ESE survey, 93\% of the patients received standard dosing, with 6 cases employing the 'Stupp' protocol, continuous dosing was given in two case and a dose-dense regimen in one case (unpublished ESE survey). It should be noted that no studies exist comparing the effect of different dosing schedules. The recommendation for this specific dose is pragmatic, as there is too little experience with different dosing schedules to recommend any variation on standard dosing.

R 3.4.4 We recommend monitoring of haematological parameters, liver function tests and careful clinical observation for potential adverse effects during treatment $(+++0)$.

\section{Reasoning}

TMZ is as an oral outpatient-based chemotherapy and is generally well-tolerated. Adverse effects reported with $\geq 10 \%$ incidence are listed in Supplementary Table 6; this information is mainly based on the use of TMZ in patients with malignant gliomas. Dose-dense regimes are associated with increased myelotoxicity (110).

In patients with aggressive pituitary tumours, fatigue is the commonest side effect of temozolomide therapy, occurring in $60 \%$ of the patients $(25,111)$. In a series of 24 patients (25), adverse effects were reported in $54 \%$ of the patients. Most were mild, similar to a report of 31 patients (12), and in a review of the 40 earliest published cases (111). Nausea/vomiting occurred in around onethird of temozolomide-treated patients consistently across studies of pituitary and other tumours $(111,112)$. Prophylactic use of anti-emetic therapy (e.g. ondansetron) is recommended during days $1-5$ of the standard therapy regimen. Importantly, myelosuppression was reported in $31 \%$ of the patients (25). Frequently, a dose reduction (Supplementary Table 7) or delay in treatment cycles can allow the patient to continue treatment $(12,25)$.

A full haematological profile should be obtained at day 22 during standard 28-day TMZ dosing cycles, and repeated weekly until neutrophil count exceeds $1.5 \times 10^{9} / \mathrm{L}$ and platelet count exceeds $100 \times 10^{9} / \mathrm{L}$ before commencing a new treatment cycle. Supplementary Table 7 outlines dose reduction and discontinuation thresholds for adverse effects as recommended by the manufacturer.

Out of a total of 190 patients, across 3 large published pituitary cohorts and the ESE survey, 29 (15\%) patients discontinued TMZ as a result of side effects
(15 with pervasive fatigue, nausea in 6 , haematological abnormalities in 3, 1 each due to headache/oedema/ hypotension, adrenal crisis, fungal septicaemia, abnormal liver function tests (LFTs) and hearing loss) (11, 12, 25, 111). A further case of hearing loss has been described (102), as has been reported in patients with non-pituitary tumours (113). In other published pituitary tumour cases, haemorrhage into cerebral metastases has been reported as a complication of severe thrombocytopaenia (114). A case of liver toxicity complicating ketoconazole therapy when TMZ was introduced was reported (115). In the wider literature, rare cases of hypersensitivity pneumonitis (116), Stevens-Johnson syndrome (117) and cholestatic hepatitis (118) have been described. Given the occasional reports of abnormal liver function and hepatitis and hepatostatic diseases, it has been recommended to monitor LFTs regularly, particularly if concurrent hepatotoxic drugs are given (119). The Temodar product information suggests monitoring LFTs at baseline, midway through first cycle, prior to each subsequent cycle and 2-4 weeks after treatment is ceased.

Haematological malignancies have been reported many years after TMZ treatment; however, in postmarketing surveillance, the absolute risk is very low $(<1$ per 10000 people treated) $(120,121)$.

Patients receiving concurrent radiotherapy, corticosteroids (or Cushing's syndrome) and dose-dense regimes may be at an increased risk of opportunistic infection, particularly Pneumocystis pneumonia. In these settings, or if significant lymphopenia develops, prophylactic trimethoprim-sulfamethoxazole or pentamidine have been recommended (122).

R 3.4.5 We suggest, in patients with rapid tumour growth in whom maximal doses of radiotherapy have not been reached, combining temozolomide with radiotherapy (Stupp protocol) $(+000)$.

\section{Reasoning}

In the 'Stupp model' (2005), patients with glioblastomas are given TMZ for a month at $75 \mathrm{mg} / \mathrm{m}^{2} /$ day concomitant with 6 weeks of fractionated EBRT followed by TMZ monotherapy using $150-200 \mathrm{mg} / \mathrm{m}^{2}$ for $5 / 28$ day cycles for a total of 6 months. This schedule was based on experimental data indicating a radio-sensitising effect of TMZ $(123,124)$. The Stupp model has been used in a small number of patients with pituitary tumours; a total of 17 are reported in the literature. The response rate was $76 \%$, i.e., higher than that reported with TMZ alone. However, some of the patients had not received prior RT $(11,125,126,127)$. 
In an Italian multi-centre study, 27/31 patients (87\%) had been treated with RT (12). The tumour had recurred after RT, except in 3 patients who received TMZ concomitantly with RT or one month thereafter. In a recent published case, a patient with a pituitary carcinoma treated with TMZ+ bevacizumab concurrent with RT, and subsequently with TMZ alone for an additional 12 cycles, complete regression was achieved and sustained five years (128).

In summary, TMZ given concurrently with RT appears beneficial; however, a recommendation for its routine use as first-line therapy cannot be made given the low quality of the evidence.

R 3.4.6 We suggest that evaluation of MGMT status by immunohistochemistry by an expert neuropathologist should be performed. High MGMT expression is suggestive of a lack of response; however, there may be exceptions $(++00)$.

\section{Reasoning}

\section{Predictors of response to temozolomide}

- MGMT TMZ acts by inserting a methyl group to DNA bases, mainly guanine. An endogenous DNA repair protein, O(6)-methylguanine methyltransferase (MGMT) can remove this methyl group and thereby potentially counteract the cytotoxic effect of TMZ. There is an association between the low MGMT expression, due to gene silencing by MGMT promoter methylation, and the response to TMZ treatment in glioblastomas (129). The value of MGMT status as a predictor of TMZ response in aggressive pituitary tumours is less clear. Promotor methylation of the gene occurs less frequently in pituitary tumours, and MGMT measured by PCR-based methods has not been associated with response to TMZ (11, 102, $107,111,130)$. The reasons are not understood and may involve mechanisms regulating MGMT expression independent of promotor methylation. Most studies in pituitary tumours have used MGMT IHC. The degree of staining has been arbitrarily divided into three categories, low (staining of $<10 \%$ of the cell nuclei), intermediate $(10-50 \%)$ and high (>50\%), alternatively low $<10 \%$, intermediate $10-90 \%$ and high $>90 \%$.

The response to TMZ in relation to MGMT status (determined by IHC) has been reported in 102 unique patients with homogenous staining in 99 cases (Fig. 2) $(11,25,102,103,104,105,107,111,131,132,133)$. Overall, it appears that a low MGMT content is mostly associated with a positive response to TMZ, a high MGMT

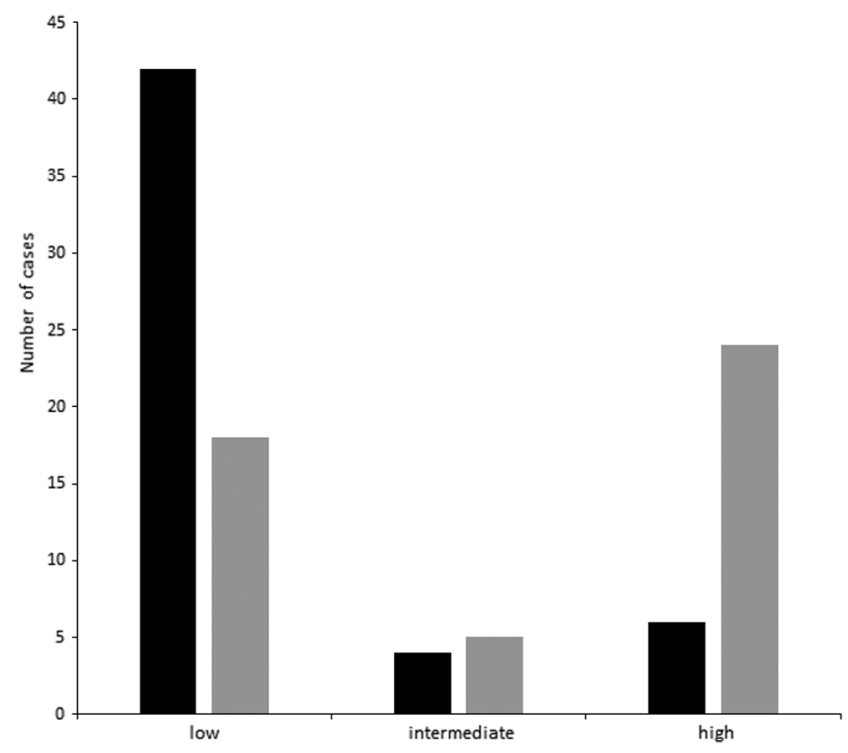

Figure 2

Response to temozolomide in 99 aggressive pituitary tumours in relation to MGMT staining (low, intermediate, high); response (solid column); no response (grey column). Response is defined as tumour regression; no response as no-tumour regression (included cases with stable tumour size).

with lack of response and notably, no response may occur also in spite of low MGMT expression. Heterogeneity within tumours, and non-standardised IHC method and expression criteria are likely to influence the relationship between MGMT expression and TMZ response.

Given the lack of other efficacious treatments for aggressive pituitary tumours and the limited experience on MGMT, a trial of TMZ therapy may be considered in patients with high MGMT expression.

- DNA mismatch repair (MMR) proteins The expression of other MMR proteins (MLH1, MSH2, MSH6 and PMS2) may be important for the cytotoxic effect of TMZ. In a study of 13 patients with aggressive pituitary tumours (9 carcinomas), intact MSH6 but not low MGMT was found to be a prognostic indicator of good response to TMZ (104). Other MMRs were not studied. Loss of MSH6 was reported to occur during progression of an atypical prolactinoma to carcinoma which may have caused resistance to TMZ treatment (134). In this patient, MGMT remained low. In other studies $(25,105)$, MSH6, MLH1, MSH2 and PMS2 did not predict the effect of TMZ.

- Markers of cell proliferation and p53 Tumourproliferative markers (Ki-67, mitotic rate) and p53 
expression have not been shown to be useful predictors of the response to TMZ $(12,25,104,107)$.

R 3.4.7 In patients responding to first-line temozolomide, as assessed after 3 cycles, we suggest treatment to be continued for at least 6 months in total, with consideration for longer duration if continued therapeutic benefit is observed (+000).

\section{Reasoning}

In patients with glioblastomas, the standard treatment duration is 6-12 months based on a 6-month treatment protocol (135). In some patients, however, treatment is continued for several years based on good tolerability and effect (136). In the literature on pituitary tumours, the length of treatment duration with a first course of TMZ has varied, and the reasons for discontinuation were often not reported. The time of follow-up after discontinuation has ranged from 2 to 33 months. In the ESE survey, the median treatment duration was 9 months with a range of 1-36 months, and the median time of follow-up after TMZ discontinuation was 21 months, interquartile range being 11-42 (unpublished ESE survey). Often, treatment duration was predetermined at the outset of treatment based on local protocols. Whether a longer treatment period in responding patients improves the chance of obtaining a sustained remission cannot be answered by the existing observational studies. It is clear that with longer observation, fewer patients remain in remission. In the North-European multi-centre study, responding patients decreased from $48 \%$ at the time of TMZ discontinuation to $33 \%$ after 32 months (25). In the French multi-centre study, the percentage with sustained response decreased from $51 \%$ at the time of $\mathrm{TMZ}$ discontinuation to $45 \%$ at last follow-up at 16 months (0-72) after drug discontinuation, with a median relapsefree survival post-TMZ treatment of 30 months (18-51). The median survival was 44 months (42-infinity) among responders and 16 months (9-25) among non-responders (11). In the Italian multi-centre study on 31 patients, progression-free survival at 2 years in the entire cohort was $48 \%$ (95\% CI 30-66\%) (12). In the ESE survey, TMZ treatment durations in responders, progressors and patients with a stable disease were 13.1 (95\% CI 11.314.9), 5.7 (CI 4.7-6.7) and 10.6 (CI 8.5-12.3) months, respectively (unpublished ESE survey). Since it is likely that treatment was continued for a longer time in responders and shorter in those with adverse effects, conclusions on a cause-effect relation cannot be drawn.
R 3.4.8 In patients with rapid tumour progression on temozolomide treatment, we suggest a trial with other systemic cytotoxic therapy. Given the variety of chemotherapeutic agents that have been reported, we cannot suggest a particular regimen (+000).

\section{Reasoning}

- Other cytotoxic drugs as first-line medical treatment Historically, a variety of cytotoxic drugs have been used in the treatment of aggressive pituitary tumours/carcinomas, of which lomustine (CCNU) in combination with 5-FU, based on their ability to penetrate into the brain, has been the most commonly employed. All evidence is based on case reports. There are no reports on complete tumour regression, but in some tumours, partial, usually transient, regression and/or stabilisation has been achieved (137). In a series of seven patients with functioning tumours, (four carcinomas) treated with CCNU/5-FU $(138,139)$, there was a transient response in a single case, a locally aggressive prolactinoma. In two aggressive somatotroph tumours, partial remissions were reported, in one case by a combination of doxorubicin and CCNU (140), in the other by methotrexate and 5-FU following extensive surgery (141). In a giant prolactinoma invading the cerebral tissue, four courses of CCNU, procarbazine and etoposide lead to improvement of vision and halted tumour growth for 12 months (142), but a subsequent course given with the onset of tumour progression was not effective. In 2 case reports of corticotroph tumour, cisplatin (carboplatin)-etoposide combination was found to result in partial regression for a limited period of time $(143,144)$. In a case of a corticotroph carcinoma, four cycles of cyclophosphamide, adriamycin and 5-FU lead to a stabilisation of systemic metastases for 3 years (145). In a TSH-secreting carcinoma, a combination of cyclophosphamide, 5-FU and adriamycin lead to 50\% reduction of metastatic pulmonary lesions. The effect lasted for a couple of months (93). Combinations of cisplatin, procarbazine, lomustine and vincristine given to three patients with metastatic prolactinomas were not effective (9).

In the ESE survey, cytotoxic agents were used as first-line therapy in six patients with aggressive pituitary tumours (lomustine in 2 cases, etoposide in 2, carboplatin or cisplatin and etoposide in 2) (unpublished ESE survey). Partial regression was seen in one case with combination of carboplatin and etoposide, and in another case by using lomustine monotherapy; progression was seen in the other four cases. Significant side effects were seen in 
cases using etoposide including cytopaenias and nausea/ vomiting.

R 3.4.9 In patients who develop a recurrence following response to temozolomide treatment, we suggest a second trial of 3 cycles of temozolomide $(+000)$.

\section{Reasoning}

\section{Second attempt with $T M Z \pm$ combinations}

There is little experience of a second treatment course with TMZ in patients who initially had responded to the drug, but in whom the tumours relapsed/progressed after treatment discontinuation. In total, 16 patients in 6 studies have been reported $(11,12,25,115,134)$ (unpublished ESE survey). In 15 patients, TMZ was given as monotherapy, in one patient (134) in combination with other drugs. Partial remission was achieved in 1 of 16 patients, 2 had stable disease and 13 had progression.

\section{Potential targeted therapies}

Raf/MEK/ERK and PI3K/Akt/mTOR pathways are upregulated in pituitary tumours (146). Preclinical and clinical studies suggest that new targeted therapies may be useful for controlling pituitary tumour growth (147, $148,149,150,151)$. However, everolimus was tried in 5 patients with aggressive pituitary tumours or carcinomas without success $(44,152)$. There were 3 cases among the ESE cohort in whom everolimus was used; all had disease progression (unpublished ESE survey).

There is some evidence supporting the use of tyrosine kinase inhibitors targeting the VEGFR pathway in the treatment of pituitary tumours (153, 154, 155, 156). Lapatanib $(n=5)$, sunitinib $(n=1)$ and erlotinib $(n=1)$ have been tried in first- or second-line treatment; all but one demonstrating tumour progression, the last one, a prolactinoma, demonstrated minimal tumour shrinkage (22\%) with lapatanib (157) (unpublished ESE survey).

Finally, VEGF-targeted therapy (bevacizumab) has been tried with some success in a few patients. Ortiz reported a 44-year-old male with a silent corticotroph pituitary carcinoma in whom prolonged tumour stabilisation was achieved (158). As monotherapy, bevacizumab was used in 2 cases as second-line therapy after progression on TMZ (unpublished ESE survey): in one case, a partial response was seen after 3 months, while the other exhibited stable disease. There was an additional case demonstrating progressive disease with bevacizumab in the setting of third-line therapy. Bevacizumab has also been used in combination with a second course of TMZ in 3 patients,
1 associated with a partial response (unpublished ESE survey).

\section{Peptide receptor radionuclide therapy (PPRT)}

Somatostatin receptors (types 1,5 and 2) arewidelyexpressed in different pituitary tumour subtypes (81). Moreover, pituitary uptake of 68Ga-DOTATATE or other radiolabeled somatostatin analogues has been demonstrated on PET/ CT $(159,160)$, suggesting that PPRT could be an option for pituitary tumours, as described for neuroendocrine tumours $(161,162)$, including pituitary metastasis (163). Fourteen patients with aggressive pituitary tumours (lactotroph $(n=5)$, gonadotroph $(n=3)$, corticotroph $(n=2)$ somatotroph $(n=3)$ and mixed somatolactotroph $(n=1))$ treated with PPRT are reported in the literature. Tumour uptake was assessed by octreoscan or 68Ga-DOTATATE PET/CT. Four patients were treated with 111Indium-DPTAoctreotide $(164,165), 4$ with 177Lutetium DOTATATE $(25$, $166,167), 3$ with 90Yttrium-DOTATOC $(25,168,169)$ and 3 with 177Lutetium DOTATOC $(11,25)$. Patients received $2-4$ cycles. Two patients demonstrated significant tumour shrinkage on treatment but one did not have a hormonal response $(164,168)$. Three patients have been reported to have stable disease with follow-up of 1 year and 3.5 years in 2 of these patients $(165,166,167)$. Nine tumours progressed on treatment or shortly after treatment cessation $(165,167,169)$.

\subsection{Local treatment of metastatic disease}

R 3.5.1 In patients with isolated metastases, we suggest consideration of loco-regional therapies, independent of decisions regarding the need for systemic treatment $(+000)$.

\section{Reasoning}

In the case of localised low-burden disease at ectopic sites such as bone and/or hepatic metastases, we recommend consideration of loco-regional therapeutic approaches (9, 170). These may include laparoscopic surgical resection of solitary lymph node metastases, focused beam external radiotherapy and/or liver-directed approaches such as chemo or bland embolisation or radio or microwave ablation in the setting of hepatic tumour deposits.

\section{Follow-up of an aggressive pituitary tumour}

R 4.1 We recommend that imaging (MRI in most instances) should be performed every 3-12 months as 
guided by prior tumour growth rate and/or location of tumour (proximity to vital structures) (+000).

\section{Reasoning}

MRI is recommended in preference to computed axial tomography (CAT); however, CAT scan without contrast enhancement may assess skull-base lesions or explore possible tumoural calcification in differential diagnosis (171). Imaging frequency is best determined on an individualised basis, commonly every 6-12 months, but factoring in (i) the prior growth trajectory of the tumour, (ii) proliferative markers and (iii) active treatment regimens such as TMZ. In general, imaging following 3 cycles of TMZ (i.e. 3 months) is recommended. In addition to conventional imaging studies (MRI, CAT), various functional imaging studies including fluoro-deoxyglucose (FDG)-PET and somatostatin receptor (SSTR)-PET may be indicated to either better stage disease or to assess suitability for PRRT.

R 4.2 We recommend that full endocrine evaluation should be performed every $3-12$ months as guided by the clinical context $(+000)$.

\section{Reasoning}

In secretory tumours where a biomarker of tumour response to therapy is available, such as serum prolactin or ACTH, and where response to treatment is being assessed, biomarker measurement on a 3-4 month basis is recommended. In addition, given treatment-related hypopituitarism, particularly radiation effects on pituitary endocrine function, which can occur many years following therapy, we recommend a full endocrine evaluation to monitor adrenal, thyroid and sex steroid functions at least yearly, or more often if clinical symptoms suggest dysfunction (28).

R 4.3 We recommend lifelong follow-up of patients with aggressive pituitary tumours (++00).

\section{Reasoning}

Evolution of a more rapid growth rate and/or transformation to a pituitary carcinoma may occur years after initial identification of an aggressive pituitary tumour. Times for development of complications of treatment, such as radiation-induced hypopituitarism or secondary malignancies are also well recognised not to emerge for many years. Therefore, we recommend lifelong follow-up of aggressive pituitary tumours with endocrine and imaging assessments at intervals as outlined earlier.

\section{Special circumstances}

a. Paediatric Pituitary tumours in childhood and adolescence are relatively rare. In children, $90 \%$ of pituitary tumours are functional, while $10 \%$ are non-functional. Giant pituitary tumours are very rare in the paediatric population, with the majority being prolactinomas and/ or acromegaly. They are invasive and more aggressive in nature, i.e., resistant to DA therapy and other therapeutic modalities $(172,173)$.

Although extremely rare, 2 paediatric pituitary carcinomas have been described in two girls aged 9 and 16. These tumours were null cell $(n=1)$ and Crooke cell carcinoma $(n=1)$ with multiple liver, intracranial and intraspinal metastases leading to patient death despite multiple treatments $(169,174)$.

Three patients with aggressive prolactinomas diagnosed at 13, 14 and 16 years of age ( 2 girls and one boy) and a 13-year-old girl with aggressive Cushing's disease have all been successfully treated with TMZ for 6 , 12,12 and 25 cycles $(11,132,175)$. Follow-up data on these cases are limited. Despite the rarity and paucity of data, these recommendations can be used to guide clinical decision making in paediatric patients.

b. Elderly Pituitary tumours in the elderly (patients older than 65 (176) are mostly clinically non-functioning (NFPA), although in general, they stain positive for gonadotroph hormones (177, 178). Most pituitary tumours in this age group are large, slowly growing invasive tumours $(179,180)$. Low growth rate of tumour remnants is reported by some (in $21 \%$ of the patients despite subtotal and partial tumour resections), while other authors report progression rates comparable in elderly and young patients $(178,179,180)$. There is no absolute contraindication to either radiotherapy or oncological drugs in the elderly. Importantly, treatment decisions in aggressive pituitary tumours and pituitary carcinomas in the elderly should take into account life expectancy and comorbidities.

Pituitary carcinomas in the elderly are rare, with malignant lactotroph, corticotroph or gonadotroph FSH tumours reported as either single case reports or in small series of pituitary carcinomas $(9,181,182)$. The experience of TMZ in elderly patients with aggressive pituitary tumours is limited, but case reports indicate that they may respond just as well. Age was not 
predictive of tumour response in recent large series $(11,12,25)$ (unpublished ESE survey) with similar response in patients older than 65 years as compared to younger patients.

c. Fertility There are no particular recommendations to guide fertility discussions for TMZ, but general recommendations are advised, as with any other chemotherapeutic agents that may be used. Most patients with aggressive pituitary tumours are extensively treated which is expected to affect their fertility capabilities. However, improvements in fertility therapies (IVF facilitation) have led to an increasing number of pregnancies in patients harbouring pituitary tumours but none was an aggressive pituitary tumour.

Contraception is needed during and after chemotherapy. The post-chemotherapy delay is 6 months for a woman and 1-2 years for a man. Any chemotherapy may be associated with some risk of gonadal toxicity, and patients of childbearing age should be informed of the risk before starting any chemotherapy. In men, oligo-azoospermia has been described even with TMZ, sometimes permanently after the first cycle of chemotherapy. Sperm cryoconservation should be advised prior to commencement. In women, the risk of chemotherapy-induced premature ovarian failure is significantly affected by patient age. Consultation with a fertility specialist is advised to discuss the preservation of oocytes, ovaries or embryos.

d. Pregnancy The improved management of pituitary tumours (medical and surgical therapies) as well as improvements in fertility therapies has led to an increasing number of pregnancies in patients harbouring pituitary tumours. No specific studies in pregnancy are reported but recent reviews on pituitary tumour management in pregnancy in general have provided valuable recommendations for close follow-up during the course of pregnancy, which is in most cases favourable (183). Pregnancy in most patients does not accelerate tumour growth, particularly in treated macroadenomas (lactotroph or somatotroph) as well as corticotroph tumours in the setting of Nelson's syndrome, compared with its natural course before pregnancy $(183,184,185)$.

\section{Perspectives}

The publication of the ESE clinical practice guidelines on aggressive pituitary tumours and carcinomas will hopefully improve identification and treatment of these rare tumours. Future efforts, similar to other European networks working on rare endocrine tumours, should combine the efforts of researchers and clinicians to establish an international register for this rare disorder. Our recent experience in compiling the European survey on aggressive pituitary tumours highlights many clinicians who are interested in developing such an international clinical register. The overall aim of such a register would be to work towards attaining consensus in diagnosis and foster improved treatment and follow-up strategies for these patients. Such registers can facilitate the establishment of clinical trials and biobanking of tumour specimens leads to improved understanding of the aetio-pathogenesis of these tumours and characterises improved prognostic and therapeutic markers. Research on these rare aggressive pituitary tumours is likely to reveal new molecular mechanisms of tumour growth that may allow the identification of new therapeutic targets.

A multidisciplinary approach to these tumours is key for both clinical management of patients and research. An international consortium supported by scientific societies is desired.

\section{Supplementary data}

This is linked to the online version of the paper at https://doi.org/10.1530/ EJE-17-0796.

\section{Declaration of interest}

Research contracts: GR (Novartis and Ipsen), PB (Novartis); Consulting: GR (Lectures for Ipsen and Novartis), PB (Advisory Boards of Pfizer and lectures for Novartis, Ipsen and Pfizer), AH (Strongbridge, Ferring, Ipsen, Lexicon, Novo Nordisk, Novartis), AMC (lectures for Ipsen and Novartis), SP (lectures for Ipsen, Novartis, and Pfizer, Advisory board member for Ipsen and Novartis), VP (lectures for Novartis and Pfizer). Other(s): AH (Endocrine Society: Associate Editor JCEM) and Pituitary Society: President Elect). The authors declare that there is no conflict of interest that could be perceived as prejudicing the impartiality of these guidelines.

Funding

These guidelines were sponsored by the European Society of Endocrinology.

\section{Acknowledgements}

Michael Buchfelder, Jean François Bonneville, Philippe Chanson, James Findling, Ashley Grossman, Jens Otto Jorgensen, Gregory Kaltsas and Ed Laws are thanked to their valuable review of these guidelines. Special thanks need to go to Alex Harrison (for the logistical support with the consensus meeting organisation).

\section{References}

1 Daly AF, Rixhon M, Adam C, Dempegioti A, Tichomirowa MA $\&$ Beckers A. High prevalence of pituitary adenomas: a cross- 
sectional study in the province of Liege, Belgium. Journal of Clinical Endocrinology and Metabolism 200691 4769-4775. (https://doi. org/10.1210/jc.2006-1668)

2 Fernandez A, Karavitaki N \& Wass JA. Prevalence of pituitary adenomas: a community-based, cross-sectional study in Banbury (Oxfordshire, UK). Clinical Endocrinology 201072 377-382. (https://doi.org/10.1111/j.1365-2265.2009.03667.x)

3 Raappana A, Koivukangas J, Ebeling T \& Pirila T. Incidence of pituitary adenomas in Northern Finland in 1992-2007. Journal of Clinical Endocrinology and Metabolism 201095 4268-4275. (https://doi.org/10.1210/jc.2010-0537)

4 Tampourlou M, Ntali G, Ahmed S, Arlt W, Ayuk J, Byrne JV, Chavda S, Cudlip S, Gittoes N, Grossman A et al. Outcome of nonfunctioning pituitary adenomas that regrow after primary treatment: a study from two large UK centers. Journal of Clinical Endocrinology and Metabolism 2017102 1889-1897. (https://doi.org/10.1210/ jc.2016-4061)

5 Saeger W, Lüdecke DK, Buchfelder M, Fahlbusch R, Quabbe HJ \& Petersenn S. Pathohistological classification of pituitary tumors: 10 years of experience with the German Pituitary Tumor Registry. European Journal of Endocrinology 2007156 203-216. (https://doi. org/10.1530/eje.1.02326)

6 Trouillas J, Roy P, Sturm N, Dantony E, Cortet-Rudelli C, Viennet G, Bonneville JF, Assaker R, Auger C, Brue T et al. A new prognostic clinicopathological classification of pituitary adenomas: a multicentric case-control study of 410 patients with 8 years postoperative follow-up. Acta Neuropathologica 2013126 123-135. (https://doi.org/10.1007/s00401-013-1084-y)

7 Zada G, Woodmansee WW, Ramkissoon S, Amadio J, Nose V \& Laws ER Jr. Atypical pituitary adenomas: incidence, clinical characteristics, and implications. Journal of Neurosurgery $2011 \mathbf{1 1 4}$ 336-344. (https://doi.org/10.3171/2010.8.JNS10290)

8 Del Basso De Caro M, Solari D, Pagliuca F, Villa A, Guadagno E, Cavallo LM, Colao A, Pettinato G \& Cappabianca P. Atypical pituitary adenomas: clinical characteristics and role of ki-67 and p53 in prognostic and therapeutic evaluation. A series of 50 patients. Neurosurgical Review 201640 105-114. (https://doi.org/10.1007/ s10143-016-0740-9)

9 Pernicone PJ, Scheithauer BW, Sebo TJ, Kovacs KT, Horvath E, Young WF Jr, Lloyd RV, Davis DH, Guthrie BL \& Schoene WC. Pituitary carcinoma: a clinicopathologic study of 15 cases. Cancer 199779 804-812. (https://doi.org/10.1002/(SICI)10970142(19970215)79:4<804::AID-CNCR18>3.0.CO;2-3)

10 Heaney A. Management of aggressive pituitary adenomas and pituitary carcinomas. Journal of Neuro-Oncology 2014117 459-468. (https://doi.org/10.1007/s11060-014-1413-6)

11 Lasolle H, Cortet C, Castinetti F, Cloix L, Caron P, Delemer B, Desailloud R, Jublanc C, Lebrun-Frenay C, Sadoul JL et al. Temozolomide treatment can improve overall survival in aggressive pituitary tumors and pituitary carcinomas. European Journal of Endocrinology 2017176 769-777. (https://doi. org/10.1530/EJE-16-0979)

12 Losa M, Bogazzi F, Cannavo S, Ceccato F, Curtò L, De Marinis L, Iacovazzo D, Lombardi G, Mantovani G, Mazza E et al. Temozolomide therapy in patients with aggressive pituitary adenomas or carcinomas. Journal of Neuro-Oncology $2016 \mathbf{1 2 6}$ 519-525. (https://doi.org/10.1007/s11060-015-1991-y)

13 Miermeister CP, Petersenn S, Buchfelder M, Fahlbusch R, Ludecke DK, Holsken A, Bergmann M, Knappe HU, Hans VH, Flitsch J et al. Histological criteria for atypical pituitary adenomas - data from the German pituitary adenoma registry suggests modifications. Acta Neuropathologica Communications 20153 50. (https://doi. org/10.1186/s40478-015-0229-8)

14 Raverot G, Vasiljevic A, Jouanneau E \& Trouillas J. A prognostic clinicopathologic classification of pituitary endocrine tumors.
Endocrinology Metabolism Clinics of North America 201544 11-18. (https://doi.org/10.1016/j.ecl.2014.10.001)

15 Saeger W, Petersenn S, Schöfl C, Knappe UJ, Theodoropoulou M, Buslei R \& Honegger J. Emerging histopathological and genetic parameters of pituitary adenomas: clinical impact and recommendation for future WHO classification. Endocrine Pathology 201627 115-122. (https://doi.org/10.1007/s12022-016-9419-6)

16 Bollerslev J, Rejnmark L, Marcocci C, Shoback DM, Sitges-Serra A, van Biesen W, Dekkers OM \& Endocrinology ESo. European Society of Endocrinology Clinical Guideline: treatment of chronic hypoparathyroidism in adults. European Journal of Endocrinology 2015 173 G1-G20. (https://doi.org/10.1530/EJE-15-0628)

17 Dekkers OM \& Burman P. ESE guidelines, why and how. European Journal of Endocrinology 2015173 E1-E2. (https://doi.org/10.1530/ EJE-15-0625)

18 Andrews JC, Schünemann HJ, Oxman AD, Pottie K, Meerpohl JJ, Coello PA, Rind D, Montori VM, Brito JP, Norris S et al. GRADE guidelines: 15. Going from evidence to recommendationdeterminants of a recommendation's direction and strength. Journal of Clinical Epidemiology 201366 726-735. (https://doi.org/10.1016/j. jclinepi.2013.02.003)

19 Honegger J, Zimmermann S, Psaras T, Petrick M, Mittelbronn M, Ernemann U, Reincke M \& Dietz K. Growth modelling of nonfunctioning pituitary adenomas in patients referred for surgery. European Journal of Endocrinology 2008158 287-294. (https://doi. org/10.1530/EJE-07-0502)

20 Bi WL, Horowtiz P, Greenwald N, Abedalthagafi M, Agarwalla PK, Gibson WJ, Mei Y, Schumacher SE, Ben-David U, Chevalier A et al. Landscape of genomic alterations in pituitary adenomas. Clinical Cancer Research 201623 1841-1851. (https://doi.org/10.1158/10780432.ccr-16-0790)

21 Chatzellis E, Alexandraki KI, Androulakis II \& Kaltsas G. Aggressive pituitary tumors. Neuroendocrinology 2015101 87-104. (https://doi. org/10.1159/000371806)

22 Maiter D \& Delgrange E. Therapy of endocrine disease: the challenges in managing giant prolactinomas. European Journal of Endocrinology 2014170 R213-R227. (https://doi.org/10.1530/EJE-14-0013)

23 Shimon I. Giant prolactinomas: multi-modal approach to achieve tumor control. Endocrine 201756 227-228. (https://doi.org/10.1007/ s12020-016-1225-x)

24 Zemmoura I, Wierinckx A, Vasiljevic A, Jan M, Trouillas J \& Francois P. Aggressive and malignant prolactin pituitary tumors: pathological diagnosis and patient management. Pituitary 201316 515-522. (https://doi.org/10.1007/s11102-012-0448-y)

25 Bengtsson D, Schroder HD, Andersen M, Maiter D, Berinder K, Feldt Rasmussen U, Rasmussen AK, Johannsson G, Hoybye C, van der Lely AJ et al. Long-term outcome and MGMT as a predictive marker in 24 patients with atypical pituitary adenomas and pituitary carcinomas given treatment with temozolomide. Journal of Clinical Endocrinology and Metabolism 2015100 1689-1698. (https://doi. org/10.1210/jc.2014-4350)

26 Moisi M, Cruz AS, Benkers T, Rostad S, Broyles FB, Yuen K \& Mayberg M. Treatment of aggressive prolactin-secreting pituitary adenomas with adjuvant temozolomide chemotherapy: a review. Cureus 20168 e658. (https://doi.org/10.7759/cureus.658)

27 Tufton N, Shapiro L, Srirangalingam U, Richards P, Sahdev A, Kumar AV, McAndrew L, Martin L, Berney D, Monson J et al. Outcomes of annual surveillance imaging in an adult and paediatric cohort of succinate dehydrogenase B mutation carriers. Clinical Endocrinology 201786 286-296. (https://doi.org/10.1111/cen.13246)

28 Cortet-Rudelli C, Bonneville JF, Borson-Chazot F, Clavier L, Coche Dequéant B, Desailloud R, Maiter D, Rohmer V, Sadoul JL, Sonnet E et al. Post-surgical management of non-functioning pituitary adenoma. Annales d'Endocrinologie 201576 228-238. (https://doi.org/10.1016/j. ando.2015.04.003) 
29 Lloyd RV, Osamura R, Klöppel G \& Rosai J. Pathology and Genetics of Tumours of Endocrine Organs. IARC WHO Classification of Tumours, No 8. Lyon: IARC press, 2017.

30 Lloyd RV, Kovacs K, Young WF Jr, Farrel WE, Asa SL, Trouillas J, Kontogeorgos G, Sano T, Scheithauer B \& Horvath E. Pituitary Tumours: Introduction. In Chapter 1: Tumours of the Pituitary. IARC WHO Classification of Tumours, No 10. Eds Lloyd RV, Osamura RY, Klöppel G, Rosai J. Lyon: IARC Press, 2004.

31 Kovacs K, Rotondo F, Horvath E, Syro LV, Di Ieva A, Cusimano MD \& Munoz DG. Letter to the editor. Endocrine Pathology 201526 93-94. (https://doi.org/10.1007/s12022-014-9342-7)

32 Righi A, Agati P, Sisto A, Frank G, Faustini-Fustini M, Agati R, Mazzatenta D, Farnedi A, Menetti F, Marucci G et al. A classification tree approach for pituitary adenomas. Human Pathology 201243 1627-1637. (https://doi.org/10.1016/j.humpath.2011.12.003)

33 Di Ieva A, Rotondo F, Syro LV, Cusimano MD \& Kovacs K. Aggressive pituitary adenomas - diagnosis and emerging treatments. Nature Reviews Endocrinology 201410 423-435. (https://doi.org/10.1038/ nrendo.2014.64)

34 Thapar K, Scheithauer BW, Kovacs K, Pernicone PJ \& Laws ER Jr. p53 expression in pituitary adenomas and carcinomas: correlation with invasiveness and tumor growth fractions. Neurosurgery 199638 765-770. (https://doi.org/10.1227/00006123-199604000-00027)

35 Gejman R, Swearingen B \& Hedley-Whyte ET. Role of Ki-67 proliferation index and p53 expression in predicting progression of pituitary adenomas. Human Pathology 200839 758-766. (https://doi. org/10.1016/j.humpath.2007.10.004)

36 Raverot G, Dantony E, Beauvy J, Vasiljevic A, Mikolasek S, BorsonChazot F, Jouanneau E, Roy P \& Trouillas J. Risk of recurrence in pituitary neuroendocrine tumors: a prospective study using a fivetiered classification. Journal of Clinical Endocrinology and Metabolism 2017102 3368-3374. (https://doi.org/10.1210/jc.2017-00773)

37 Delgrange E, Maiter D \& Donckier J. Effects of the dopamine agonist cabergoline in patients with prolactinoma intolerant or resistant to bromocriptine. European Journal of Endocrinology 1996134 454-456. (https://doi.org/10.1530/eje.0.1340454)

38 Delgrange E, Vasiljevic A, Wierinckx A, François P, Jouanneau E, Raverot G \& Trouillas J. Expression of estrogen receptor alpha is associated with prolactin pituitary tumor prognosis and supports the sex-related difference in tumor growth. European Journal of Endocrinology 2015172 791-801. (https://doi.org/10.1530/EJE-140990)

39 Cooper O. Silent corticotroph adenomas. Pituitary 201518 225-231. (https://doi.org/10.1007/s11102-014-0624-3)

40 Mete O, Gomez-Hernandez K, Kucharczyk W, Ridout R, Zadeh G, Gentili F, Ezzat S \& Asa SL. Silent subtype 3 pituitary adenomas are not always silent and represent poorly differentiated monomorphous plurihormonal Pit-1 lineage adenomas. Modern Pathology 201629 131-142. (https://doi.org/10.1038/modpathol.2015.151)

41 Balogun JA, Monsalves E, Juraschka K, Parvez K, Kucharczyk W, Mete O, Gentili F \& Zadeh G. Null cell adenomas of the pituitary gland: an institutional review of their clinical imaging and behavioral characteristics. Endocrine Pathology 201526 63-70. (https://doi.org/10.1007/s12022-014-9347-2)

42 Melcescu E, Gannon AW, Parent AD, Fratkin JF, Nicholas WC, Koch CA \& Galhom A. Silent or subclinical corticotroph pituitary macroadenoma transforming into Cushing disease: 11-year follow-up. Neurosurgery 201372 E144-E146. (https://doi. org/10.1227/NEU.0b013e3182750850)

43 Karavitaki N, Ansorge O \& Wass JA. Silent corticotroph adenomas. Arquivos Brasileiros de Endocrinologia and Metabologia 200751 1314-1318. (https://doi.org/10.1590/S0004-27302007000800017)

44 Jouanneau E, Wierinckx A, Ducray F, Favrel V, Borson-Chazot F, Honnorat J, Trouillas J \& Raverot G. New targeted therapies in pituitary carcinoma resistant to temozolomide. Pituitary 201215 37-43. (https://doi.org/10.1007/s11102-011-0341-0)
45 Daems T, Verhelst J, Michotte A, Abrams P, De Ridder D \& Abs R. Modification of hormonal secretion in clinically silent pituitary adenomas. Pituitary 200912 80-86. (https://doi.org/10.1007/s11102008-0085-7)

46 Richardson TE, Mathis DA, Mickey BE, Raisanen JM, Burns DK, White CL \& Hatanpaa KJ. Clinical outcome of silent subtype III pituitary adenomas diagnosed by immunohistochemistry. Journal of Neuropathology and Experimental Neurology 201574 1170-1177. (https://doi.org/10.1093/jnen/74.12.1170)

47 Beckers A, Aaltonen LA, Daly AF \& Karhu A. Familial isolated pituitary adenomas (FIPA) and the pituitary adenoma predisposition due to mutations in the aryl hydrocarbon receptor interacting protein (AIP) gene. Endocrine Reviews 201334 239-277. (https://doi. org/10.1210/er.2012-1013)

48 Tichomirowa MA, Barlier A, Daly AF, Jaffrain-Rea ML, Ronchi C, Yaneva M, Urban JD, Petrossians P, Elenkova A, Tabarin A et al. High prevalence of AIP gene mutations following focused screening in young patients with sporadic pituitary macroadenomas. European Journal of Endocrinology 2011165 509-515. (https://doi.org/10.1530/ EJE-11-0304)

49 Trouillas J, Labat-Moleur F, Sturm N, Kujas M, Heymann MF, Figarella-Branger D, Patey M, Mazucca M, Decullier E, Verges B et al. Pituitary tumors and hyperplasia in multiple endocrine neoplasia type 1 syndrome (MEN1): a case-control study in a series of 77 patients versus 2509 non-MEN1 patients. American Journal of Surgical Pathology 200832 534-543. (https://doi.org/10.1097/ PAS.0b013e31815ade45)

50 Caimari F \& Korbonits M. Novel genetic causes of pituitary adenomas. Clinical Cancer Research 201622 5030-5042. (https://doi. org/10.1158/1078-0432.CCR-16-0452)

51 Ciric I, Ragin A, Baumgartner C \& Pierce D. Complications of transsphenoidal surgery: results of a national survey, review of the literature, and personal experience. Neurosurgery 199740 225-236. (https://doi.org/10.1097/00006123-199702000-00001)

52 Powell M \& Grossman A. Quality indicators in pituitary surgery: a need for reliable and valid assessments. What should be measured? Clinical Endocrinology 201684 485-488. (https://doi.org/10.1111/ cen.13007)

53 Minniti G, Clarke E, Scaringi C \& Enrici RM. Stereotactic radiotherapy and radiosurgery for non-functioning and secreting pituitary adenomas. Reports of Practical Oncology and Radiotherapy 201621 370-378. (https://doi.org/10.1016/j.rpor.2014.09.004)

54 Ding D, Starke RM \& Sheehan JP. Treatment paradigms for pituitary adenomas: defining the roles of radiosurgery and radiation therapy. Journal of Neuro-Oncology 2014117 445-457. (https://doi. org/10.1007/s11060-013-1262-8)

55 Sheehan JP, Starke RM, Mathieu D, Young B, Sneed PK, Chiang VL, Lee JY, Kano H, Park KJ, Niranjan A et al. Gamma Knife radiosurgery for the management of nonfunctioning pituitary adenomas: a multicenter study. Journal of Neurosurgery 2013119 446-456. (https://doi.org/10.3171/2013.3.JNS12766)

56 Starke RM, Williams BJ, Jane JA \& Sheehan JP. Gamma Knife surgery for patients with nonfunctioning pituitary macroadenomas: predictors of tumor control, neurological deficits, and hypopituitarism. Journal of Neurosurgery 2012117 129-135. (https://doi.org/10.3171/2012.4.JNS112250)

57 Ayuk J \& Stewart PM. Mortality following pituitary radiotherapy. Pituitary 200912 35-39. (https://doi.org/10.1007/s11102-007-00831)

58 Burman P, van Beek AP, Biller BM, Camacho-Hübner C \& Mattsson AF. Radiotherapy, especially at young age, increases the risk for de novo brain tumors in patients treated for pituitary/sellar lesions. Journal of Clinical Endocrinology and Metabolism $2017 \mathbf{1 0 2}$ 1051-1058. (https://doi.org/10.1210/jc.2016-3402)

59 Minniti G, Traish D, Ashley S, Gonsalves A \& Brada M. Risk of second brain tumor after conservative surgery and radiotherapy for 
pituitary adenoma: update after an additional 10 years. Journal of Clinical Endocrinology and Metabolism 200590 800-804. (https://doi. org/10.1210/jc.2004-1152)

60 Norberg L, Johansson R \& Rasmuson T. Intracranial tumours after external fractionated radiotherapy for pituitary adenomas in northern Sweden. Acta Oncologica 201049 1276-1282. (https://doi. org/10.3109/02841861003782025)

61 Loeffler JS \& Shih HA. Radiation therapy in the management of pituitary adenomas. Journal of Clinical Endocrinology and Metabolism 201196 1992-2003. (https://doi.org/10.1210/jc.2011-0251)

62 Gittoes NJ, Bates AS, Tse W, Bullivant B, Sheppard MC, Clayton RN \& Stewart PM. Radiotherapy for non-function pituitary tumours. Clinical Endocrinology 199848 331-337. (https://doi.org/10.1046/ j.1365-2265.1998.00393.x)

63 Edwards AA, Swords FM \& Plowman PN. Focal radiation therapy for patients with persistent/recurrent pituitary adenoma, despite previous radiotherapy. Pituitary 200912 30-34. (https://doi. org/10.1007/s11102-008-0115-5)

64 Colao A \& Savastano S. Medical treatment of prolactinomas. Nature Reviews Endocrinology 20117 267-278. (https://doi.org/10.1038/ nrendo.2011.37)

65 Molitch ME. Management of medically refractory prolactinoma. Journal of Neuro-Oncology 2014117 421-428. (https://doi org/10.1007/s11060-013-1270-8)

66 Delgrange E, Daems T, Verhelst J, Abs R \& Maiter D. Characterization of resistance to the prolactin-lowering effects of cabergoline in macroprolactinomas: a study in 122 patients. European Journal of Endocrinology 2009160 747-752. (https://doi.org/10.1530/EJE-090012)

67 Delgrange E, Raverot G, Bex M, Burman P, Decoudier B, Devuyst F, Feldt-Rasmussen U, Andersen M \& Maiter D. Giant prolactinomas in women. European Journal of Endocrinology 2014170 31-38. (https://doi.org/10.1530/EJE-13-0503)

68 Hofland LJ, Feelders RA, de Herder WW \& Lamberts SW. Pituitary tumours: the sst/D2 receptors as molecular targets. Molecular and Cellular Endocrinology 2010326 89-98. (https://doi.org/10.1016/j. mce.2010.04.020)

69 Caron PJ, Bevan JS, Petersenn S, Flanagan D, Tabarin A, Prévost G, Maisonobe P, Clermont A \& Investigators P. Tumor shrinkage with lanreotide Autogel $120 \mathrm{mg}$ as primary therapy in acromegaly: results of a prospective multicenter clinical trial. Journal of Clinical Endocrinology and Metabolism 201499 1282-1290. (https://doi. org/10.1210/jc.2013-3318)

70 Colao A, Bronstein MD, Freda P, Gu F, Shen CC, Gadelha M, Fleseriu M, van der Lely AJ, Farrall AJ, Hermosillo Resendiz K et al. Pasireotide versus octreotide in acromegaly: a head-to-head superiority study. Journal of Clinical Endocrinology and Metabolism 201499 791-799. (https://doi.org/10.1210/jc.2013-2480)

71 Freda PU, Katznelson L, van der Lely AJ, Reyes CM, Zhao S \& Rabinowitz D. Long-acting somatostatin analog therapy of acromegaly: a meta-analysis. Journal of Clinical Endocrinology and Metabolism 200590 4465-4473. (https://doi.org/10.1210/jc.20050260)

72 Bevan JS. Clinical review: the antitumoral effects of somatostatin analog therapy in acromegaly. Journal of Clinical Endocrinology and Metabolism 200590 1856-1863. (https://doi.org/10.1210/jc.20041093)

73 Mercado M, Borges F, Bouterfa H, Chang TC, Chervin A, Farrall AJ, Patocs A, Petersenn S, Podoba J, Safari M et al. A prospective, multicentre study to investigate the efficacy, safety and tolerability of octreotide LAR (long-acting repeatable octreotide) in the primary therapy of patients with acromegaly. Clinical Endocrinology 200766 859-868. (https://doi.org/10.1111/j.1365-2265.2007.02825.x)

74 Besser GM, Burman P \& Daly AF. Predictors and rates of treatment-resistant tumor growth in acromegaly. European Journal of Endocrinology 2005153 187-193. (https://doi.org/10.1530/ eje.1.01968)

75 van der Lely AJ, Biller BM, Brue T, Buchfelder M, Ghigo E, Gomez R, Hey-Hadavi J, Lundgren F, Rajicic N, Strasburger CJ et al. Long-term safety of pegvisomant in patients with acromegaly: comprehensive review of 1288 subjects in ACROSTUDY. Journal of Clinical Endocrinology and Metabolism 201297 1589-1597. (https://doi. org/10.1210/jc.2011-2508)

76 Trainer PJ, Drake WM, Katznelson L, Freda PU, Herman-Bonert V, van der Lely AJ, Dimaraki EV, Stewart PM, Friend KE, Vance ML et $a l$. Treatment of acromegaly with the growth hormone-receptor antagonist pegvisomant. New England Journal of Medicine 2000342 1171-1177. (https://doi.org/10.1056/NEJM200004203421604)

77 Neggers SJ, Franck SE, de Rooij FW, Dallenga AH, Poublon RM, Feelders RA, Janssen JA, Buchfelder M, Hofland LJ, Jørgensen JO et al. Long-term efficacy and safety of pegvisomant in combination with long-acting somatostatin analogs in acromegaly. Journal of Clinical Endocrinology and Metabolism 201499 3644-3652. (https://doi. org/10.1210/jc.2014-2032)

78 Kuhn E \& Chanson P. Cabergoline in acromegaly. Pituitary 201720 121-128. (https://doi.org/10.1007/s11102-016-0782-6)

79 Colao A, Petersenn S, Newell-Price J, Findling JW, Gu F, Maldonado M, Schoenherr U, Mills D, Salgado LR, Biller BM et al. A 12-month phase 3 study of pasireotide in Cushing's disease. New England Journal of Medicine 2012366 914-924. (https://doi. org/10.1056/NEJMoa1105743)

80 Burman P, Edén-Engström B, Ekman B, Karlsson FA, Schwarcz E \& Wahlberg J. Limited value of cabergoline in Cushing's disease: a prospective study of a 6-week treatment in 20 patients. European Journal of Endocrinology 2016174 17-24. (https://doi.org/10.1530/ EJE-15-0807)

81 Chinezu L, Vasiljevic A, Jouanneau E, Francois P, Borda A, Trouillas J \& Raverot G. Expression of somatostatin receptors, SSTR2A and SSTR5, in 108 endocrine pituitary tumors using immunohistochemical detection with new specific monoclonal antibodies. Human Pathology 201445 71-77. (https://doi. org/10.1016/j.humpath.2013.08.007)

82 Beck-Peccoz P \& Persani L. Medical management of thyrotropinsecreting pituitary adenomas. Pituitary 20025 83-88. (https://doi. org/10.1023/A:1022360414062)

83 Amlashi FG \& Tritos NA. Thyrotropin-secreting pituitary adenomas: epidemiology, diagnosis, and management. Endocrine 201652 427-440. (https://doi.org/10.1007/s12020-016-0863-3)

84 Delgrange E, Sassolas G, Perrin G, Jan M \& Trouillas J. Clinical and histological correlations in prolactinomas, with special reference to bromocriptine resistance. Acta Neurochirurgica 2005147 751-757. (https://doi.org/10.1007/s00701-005-0498-2)

85 Oh MC \& Aghi MK. Dopamine agonist-resistant prolactinomas. Journal of Neurosurgery 2011114 1369-1379. (https://doi. org/10.3171/2010.11.JNS101369)

86 Ono M, Miki N, Kawamata T, Makino R, Amano K, Seki T, Kubo O, Hori T \& Takano K. Prospective study of high-dose cabergoline treatment of prolactinomas in 150 patients. Journal of Clinical Endocrinology and Metabolism 200893 4721-4727. (https://doi. org/10.1210/jc.2007-2758)

87 Colao A, Auriemma RS, Lombardi G \& Pivonello R. Resistance to somatostatin analogs in acromegaly. Endocrine Reviews 201132 247-271. (https://doi.org/10.1210/er.2010-0002)

88 Casar-Borota O, Heck A, Schulz S, Nesland JM, Ramm-Pettersen J, Lekva T, Alafuzoff I \& Bollerslev J. Expression of SSTR2a, but not of SSTRs 1, 3, or 5 in somatotroph adenomas assessed by monoclonal antibodies was reduced by octreotide and correlated with the acute and long-term effects of octreotide. Journal of Clinical Endocrinology and Metabolism 201398 E1730-E1739. (https://doi.org/10.1210/ jc.2013-2145) 
89 Gatto F, Feelders RA, van der Pas R, Kros JM, Waaijers M, SprijMooij D, Neggers SJ, van der Lelij AJ, Minuto F, Lamberts SW et al. Immunoreactivity score using an anti-sst2A receptor monoclonal antibody strongly predicts the biochemical response to adjuvant treatment with somatostatin analogs in acromegaly. Journal of Clinical Endocrinology and Metabolism 201398 E66-E71. (https://doi. org/10.1210/jc.2012-2609)

90 Park C, Yang I, Woo J, Kim S, Kim J, Kim Y, Sohn S, Kim E, Lee M, Park $\mathrm{H}$ et al. Somatostatin (SRIF) receptor subtype 2 and 5 gene expression in growth hormone-secreting pituitary adenomas: the relationship with endogenous srif activity and response to octreotide. Endocrine Journal 200451 227-236. (https://doi.org/10.1507/ endocrj.51.227)

91 Iacovazzo D, Carlsen E, Lugli F, Chiloiro S, Piacentini S, Bianchi A, Giampietro A, Mormando M, Clear AJ, Doglietto F et al. Factors predicting pasireotide responsiveness in somatotroph pituitary adenomas resistant to first-generation somatostatin analogues: an immunohistochemical study. European Journal of Endocrinology 2016 174 241-250. (https://doi.org/10.1530/EJE-15-0832)

92 Muhr C, Bergström M, Lundberg PO, Hartman M, Bergström K, Pellettieri L \& Långström B. Malignant prolactinoma with multiple intracranial metastases studied with positron emission tomography. Neurosurgery 198822 374-379. (https://doi.org/10.1227/00006123198802000-00017)

93 Mixson AJ, Friedman TC, Katz DA, Feuerstein IM, Taubenberger JK, Colandrea JM, Doppman JL, Oldfield EH \& Weintraub BD. Thyrotropin-secreting pituitary carcinoma. Journal of Clinical Endocrinology and Metabolism 199376 529-533. (https://doi. org/10.1210/jc.76.2.529)

94 Katznelson L. Sustained improvements in plasma ACTH and clinical status in a patient with Nelson's syndrome treated with pasireotide LAR, a multireceptor somatostatin analog. Journal of Clinical Endocrinology and Metabolism 201398 1803-1807. (https://doi. org/10.1210/jc.2013-1497)

95 Greenman Y \& Stern N. Paradoxical and atypical responses to pasireotide in aggressive ACTH-secreting pituitary tumors. Pituitary 201619 605-611. (https://doi.org/10.1007/s11102-016-0755-9)

96 Assié G, Bahurel H, Coste J, Silvera S, Kujas M, Dugué MA, Karray F, Dousset B, Bertherat J, Legmann P et al. Corticotroph tumor progression after adrenalectomy in Cushing's disease: a reappraisal of Nelson's syndrome. Journal of Clinical Endocrinology and Metabolism 200792 172-179. (https://doi.org/10.1210/jc.2006-1328)

97 van der Klaauw A, Kienitz T, Strasburger C, Smit J \& Romijn J. Malignant pituitary corticotroph adenomas: report of two cases and a comprehensive review of the literature. Pituitary 200912 57-69. (https://doi.org/10.1007/s11102-007-0080-4)

98 Blevins LS Jr, Christy JH, Khajavi M \& Tindall GT. Outcomes of therapy for Cushing's disease due to adrenocorticotropin-secreting pituitary macroadenomas. Journal of Clinical Endocrinology and Metabolism 199883 63-67. (https://doi.org/10.1210/jcem.83.1.4525)

99 Fadul CE, Kominsky AL, Meyer LP, Kingman LS, Kinlaw WB, Rhodes CH, Eskey CJ \& Simmons NE. Long-term response of pituitary carcinoma to temozolomide. Report of two cases. Journal of Neurosurgery 2006105 621-626. (https://doi.org/10.3171/ jns.2006.105.4.621)

100 Lim S, Shahinian H, Maya MM, Yong W \& Heaney AP. Temozolomide: a novel treatment for pituitary carcinoma. Lancet Oncology 20067 518-520. (https://doi.org/10.1016/S14702045(06)70728-8)

101 Syro LV, Uribe H, Penagos LC, Ortiz LD, Fadul CE, Horvath E \& Kovacs K. Antitumour effects of temozolomide in a man with a large, invasive prolactin-producing pituitary neoplasm. Clinical Endocrinology 200665 552-553. (https://doi.org/10.1111/j.13652265.2006.02653.x)

102 Bush ZM, Longtine JA, Cunningham T, Schiff D, Jane JA Jr, Vance ML, Thorner MO, Laws ER Jr \& Lopes MB. Temozolomide treatment for aggressive pituitary tumors: correlation of clinical outcome with $\mathrm{O}(6)$-methylguanine methyltransferase (MGMT) promoter methylation and expression. Journal of Clinical Endocrinology and Metabolism 201095 E280-E290. (https://doi. org/10.1210/jc.2010-0441)

103 Bruno OD, Juárez-Allen L, Christiansen SB, Manavela M, Danilowicz K, Vigovich C \& Gómez RM. Temozolomide therapy for aggressive pituitary tumors: results in a small series of patients from Argentina. International Journal of Endocrinology 20152015587893. (https://doi.org/10.1155/2015/587893)

104 Hirohata T, Asano K, Ogawa Y, Takano S, Amano K, Isozaki O, Iwai Y, Sakata K, Fukuhara N, Nishioka $\mathrm{H}$ et al. DNA Mismatch Repair Protein (MSH6) correlated with the responses of atypical pituitary adenomas and pituitary carcinomas to temozolomide: the national cooperative study by the Japan society for hypothalamic and pituitary tumors. Journal of Clinical Endocrinology and Metabolism 201398 1130-1136. (https://doi.org/10.1210/jc.2012-2924)

105 Zacharia BE, Gulati AP, Bruce JN, Carminucci AS, Wardlaw SL, Siegelin M, Remotti H, Lignelli A \& Fine RL. High response rates and prolonged survival in patients with corticotroph pituitary tumors and refractory Cushing disease from capecitabine and temozolomide (CAPTEM): a case series. Neurosurgery 201474 E447-E455. (https://doi.org/10.1227/NEU.0000000000000251)

106 Kurowska M, Tarach JS, Malicka J, Zieliński G, Maksymowicz M $\&$ Denew P. Long-term complete remission of Crooke's corticotropinoma after temozolomide treatment. Endokrynologia Polska 201667 526-533. (https://doi.org/10.5603/EP.2016.0060)

107 Raverot G, Sturm N, de Fraipont F, Muller M, Salenave S, Caron P, Chabre O, Chanson P, Cortet-Rudelli C, Assaker R et al. Temozolomide treatment in aggressive pituitary tumors and pituitary carcinomas: a French multicenter experience. Journal of Clinical Endocrinology and Metabolism 201095 4592-4599. (https://doi. org/10.1210/jc.2010-0644)

108 Bode H, Seiz M, Lammert A, Brockmann MA, Back W, Hammes HP $\&$ Thome C. SOM230 (pasireotide) and temozolomide achieve sustained control of tumour progression and ACTH secretion in pituitary carcinoma with widespread metastases. Experimental and Clinical Endocrinology and Diabetes 2010118 760-763. (https://doi. org/10.1055/s-0030-1253419)

109 Ceccato F, Lombardi G, Manara R, Emanuelli E, Denaro L, Milanese L, Gardiman MP, Bertorelle R, Scanarini M, D'Avella D et al. Temozolomide and pasireotide treatment for aggressive pituitary adenoma: expertise at a tertiary care center. Journal of Neuro-Oncology 2015122 189-196. (https://doi.org/10.1007/s11060-014-1702-0)

110 Gilbert MR, Wang M, Aldape KD, Stupp R, Hegi ME, Jaeckle KA, Armstrong TS, Wefel JS, Won M, Blumenthal DT et al. Dose-dense temozolomide for newly diagnosed glioblastoma: a randomized phase III clinical trial. Journal of Clinical Oncology 201331 4085-4091. (https://doi.org/10.1200/JCO.2013.49.6968)

111 McCormack AI, Wass JA \& Grossman. AB. Aggressive pituitary tumours: the role of temozolomide and the assessment of MGMT status. European Journal of Clinical Investigation 201141 1133-1148. (https://doi.org/10.1111/j.1365-2362.2011.02520.x)

112 Danson SJ \& Middleton MR. Temozolomide: a novel oral alkylating agent. Expert Review of Anticancer Therapy 20011 13-19. (https://doi. org/10.1586/14737140.1.1.13)

113 Ekeblad S, Sundin A, Janson ET, Welin S, Granberg D, Kindmark H, Dunder K, Kozlovacki G, Orlefors H, Sigurd M et al. Temozolomide as monotherapy is effective in treatment of advanced malignant neuroendocrine tumors. Clinical Cancer Research 200713 2986-2991. (https://doi.org/10.1158/1078-0432.CCR-06-2053)

114 Mendola M, Passeri E, Ambrosi B \& Corbetta S. Multiple cerebral hemorrhagic foci from metastases during temozolomide treatment in a patient with corticotroph pituitary carcinoma. Journal of Clinical Endocrinology and Metabolism 201499 2623-2624. (https://doi. org/10.1210/jc.2014-1183) 
115 Campderá M, Palacios N, Aller J, Magallón R, Martín P, Saucedo G, Lilienfeld $\mathrm{H} \&$ Estrada J. Temozolomide for aggressive ACTH pituitary tumors: failure of a second course of treatment. Pituitary 201619 158-166. (https://doi.org/10.1007/s11102-015-0694-x)

116 Guilleminault L, Carré P \& Diot P. Hypersensitivity pneumonitis associated with temozolomide. European Respiratory Journal 200934 526. (https://doi.org/10.1183/09031936.00065909)

117 Sarma N. Stevens-Johnson syndrome and toxic epidermal necrolysis overlap due to oral temozolomide and cranial radiotherapy. American Journal of Clinical Dermatology 200910 264-267. (https://doi. org/10.2165/00128071-200910040-00007)

118 Grieco A, Tafuri MA, Biolato M, Diletto B, Di Napoli N, Balducci N, Vecchio FM \& Miele L. Severe cholestatic hepatitis due to temozolomide: an adverse drug effect to keep in mind. Case report and review of literature. Medicine 201594 e476. (https://doi. org/10.1097/MD.0000000000000476)

119 Balakrishnan A, Ledford R \& Jaglal M. Temozolomide-induced biliary ductopenia: a case report. Journal of Medical Case Reports 20161033. (https://doi.org/10.1186/s13256-016-0804-z)

120 Neyns B, Cordera S, Joosens E, Pouratian N \& Nader P. NonHodgkin's lymphoma in patients with glioma treated with temozolomide. Journal of Clinical Oncology 200826 4518-4519. (https://doi.org/10.1200/JCO.2008.18.8177)

121 George BJ, Eichinger JB \& Richard TJ. A rare case of aplastic anemia caused by temozolomide. Southern Medical Journal 2009102 974-976. (https://doi.org/10.1097/SMJ.0b013e3181b1d2fa)

122 Neyns B, Tosoni A, Hwu WJ \& Reardon DA. Dose-dense temozolomide regimens: antitumor activity, toxicity, and immunomodulatory effects. Cancer 2010116 2868-2877. (https://doi.org/10.1002/cncr.25035)

123 Kil WJ, Cerna D, Burgan WE, Beam K, Carter D, Steeg PS, Tofilon PJ \& Camphausen $\mathrm{K}$. In vitro and in vivo radiosensitization induced by the DNA methylating agent temozolomide. Clinical Cancer Research 200814 931-938. (https://doi.org/10.1158/1078-0432.CCR-07-1856)

124 Carlson BL, Grogan PT, Mladek AC, Schroeder MA, Kitange GJ, Decker PA, Giannini C, Wu W, Ballman KA, James CD et al. Radiosensitizing effects of temozolomide observed in vivo only in a subset of O6-methylguanine-DNA methyltransferase methylated glioblastoma multiforme xenografts. International Journal of Radiation Oncology, Biology, Physics 200975 212-219. (https://doi. org/10.1016/j.ijrobp.2009.04.026)

125 Zhong C, Yin S, Zhou P \& Jiang S. Pituitary atypical adenoma or carcinoma sensitive to temozolomide combined with radiation therapy: a case report of early identification and management. Turkish Neurosurgery 201424 963-966. (https://doi.org/10.5137/10195149.JTN.9629-13.1)

126 Kamiya-Matsuoka C, Cachia D, Waguespack SG, Crane CH, Mahajan A, Brown PD, Nam JY, McCutcheon IE \& Penas-Prado M. Radiotherapy with concurrent temozolomide for the management of extraneural metastases in pituitary carcinoma. Pituitary 201619 415-421. (https://doi.org/10.1007/s11102-016-0721-6)

127 Misir Krpan A, Dusek T, Rakusic Z, Solak M, Kraljevic I, Bisof V, Ozretic D \& Kastelan D. A rapid biochemical and radiological response to the concomitant therapy with temozolomide and radiotherapy in an aggressive ACTH pituitary adenoma. Case Reports in Endocrinology 20172017 2419590. (https://doi. org $/ 10.1155 / 2017 / 2419590)$

128 Touma W, Hoostal S, Peterson RA, Wiernik A, SantaCruz KS \& Lou E. Successful treatment of pituitary carcinoma with concurrent radiation, temozolomide, and bevacizumab after resection. Journal of Clinical Neuroscience 201741 75-77. (https://doi.org/10.1016/j. jocn.2017.02.052)

129 Hegi ME, Diserens AC, Gorlia T, Hamou MF, de Tribolet N, Weller M, Kros JM, Hainfellner JA, Mason W, Mariani L et al. MGMT gene silencing and benefit from temozolomide in glioblastoma. New
England Journal of Medicine 2005352 997-1003. (https://doi. org/10.1056/NEJMoa043331)

130 Salehi F, Scheithauer BW, Kros JM, Lau Q, Fealey M, Erickson D, Kovacs K, Horvath E \& Lloyd RV. MGMT promoter methylation and immunoexpression in aggressive pituitary adenomas and carcinomas. Journal of Neuro-Oncology 2011104 647-657. (https://doi.org/10.1007/s11060-011-0532-6)

131 Losa M, Mazza E, Terreni MR, McCormack A, Gill AJ, Motta M, Cangi MG, Talarico A, Mortini P \& Reni M. Salvage therapy with temozolomide in patients with aggressive or metastatic pituitary adenomas: experience in six cases. European Journal of Endocrinology 2010163 843-851. (https://doi.org/10.1530/EJE-10-0629)

132 Whitelaw BC, Dworakowska D, Thomas NW, Barazi S, Riordan-Eva P, King AP, Hampton T, Landau DB, Lipscomb D, Buchanan CR et al. Temozolomide in the management of dopamine agonist-resistant prolactinomas. Clinical Endocrinology 201276 877-886. (https://doi. org/10.1111/j.1365-2265.2012.04373.x)

133 Annamalai AK, Dean AF, Kandasamy N, Kovacs K, Burton H, Halsall DJ, Shaw AS, Antoun NM, Cheow HK, Kirollos RW et al. Temozolomide responsiveness in aggressive corticotroph tumours: a case report and review of the literature. Pituitary 201215 276-287. (https://doi.org/10.1007/s11102-011-0363-7)

134 Murakami M, Mizutani A, Asano S, Katakami H, Ozawa Y, Yamazaki K, Ishida Y, Takano K, Okinaga H \& Matsuno A. A mechanism of acquiring temozolomide resistance during transformation of atypical prolactinoma into prolactin-producing pituitary carcinoma: case report. Neurosurgery 201168 E1761-E1767. (https://doi.org/10.1227/NEU.0b013e318217161a)

135 Mirimanoff RO, Gorlia T, Mason W, Van den Bent MJ, Kortmann RD, Fisher B, Reni M, Brandes AA, Curschmann J, Villa S et al. Radiotherapy and temozolomide for newly diagnosed glioblastoma: recursive partitioning analysis of the EORTC 26981/22981-NCIC CE3 phase III randomized trial. Journal of Clinical Oncology 200624 2563-2569. (https://doi.org/10.1200/JCO.2005.04.5963)

136 Barbagallo GM, Paratore S, Caltabiano R, Palmucci S, Parra HS, Privitera G, Motta F, Lanzafame S, Scaglione G, Longo A et al. Longterm therapy with temozolomide is a feasible option for newly diagnosed glioblastoma: a single-institution experience with as many as 101 temozolomide cycles. Neurosurgical Focus 201437 E4. (https://doi.org/10.3171/2014.9.FOCUS14502)

137 Dudziak K, Honegger J, Bornemann A, Horger M \& Mussig K. Pituitary carcinoma with malignant growth from first presentation and fulminant clinical course - case report and review of the literature. Journal of Clinical Endocrinology and Metabolism 201196 2665-2669. (https://doi.org/10.1210/jc.2011-1166)

138 Kaltsas GA, Mukherjee JJ, Plowman PN, Monson JP, Grossman AB \& Besser GM. The role of cytotoxic chemotherapy in the management of aggressive and malignant pituitary tumors. Journal of Clinical Endocrinology and Metabolism 199883 4233-4238. (https://doi. org/10.1210/jcem.83.12.5300)

139 Kaltsas GA \& Grossman AB. Malignant pituitary tumours. Pituitary 19981 69-81. (https://doi.org/10.1023/A:1009975009924)

140 Kasperlik-Zaluska AA, Wislawski J, Kaniewska J, Zborzil J, Frankiewicz E \& Zgliczyński S. Cytostatics for acromegaly. Marked improvement in a patient with an invasive pituitary tumour. Acta Endocrinologica 1987116 347-349. (https://doi.org/10.1530/ acta.0.1160347)

141 Asai A, Matsutani M, Funada N \& Takakura K. Malignant growth hormone-secreting pituitary adenoma with hematogenous dural metastasis: case report. Neurosurgery 198822 1091-1094. (https://doi. org/10.1227/00006123-198806010-00023)

142 Petterson T, MacFarlane IA, MacKenzie JM \& Shaw MD. Prolactin secreting pituitary carcinoma. Journal of Neurology, Neurosurgery, and Psychiatry 199255 1205-1206. (https://doi.org/10.1136/ jnnp.55.12.1205) 
143 Cornell RF, Kelly DF, Bordo G, Carroll TB, Duong HT, Kim J, Takasumi Y, Thomas JP, Wong YL \& Findling JW. Chemotherapyinduced regression of an adrenocorticotropin-secreting pituitary carcinoma accompanied by secondary adrenal insufficiency. Case Reports in Endocrinology 20132013 675298. (https://doi. org/10.1155/2013/675298)

144 He L, Forbes JA, Carr K, Highfield Nickols H, Utz A, Moots P \& Weaver K. Response of silent corticotroph pituitary carcinoma to chemotherapy: case report. Journal of Neurosurgery Sci $2016 \mathbf{6 0}$ 272-280.

145 Kaiser FE, Orth DN, Mukai K \& Oppenheimer JH. A pituitary parasellar tumor with extracranial metastases and high, partially suppressible levels of adrenocorticotropin and related peptides. Journal of Clinical Endocrinology and Metabolism 198357 649-653. (https://doi.org/10.1210/jcem-57-3-649)

146 Dworakowska D \& Grossman AB. The pathophysiology of pituitary adenomas. Best Practice and Research: Clinical Endocrinology and Metabolism 200923 525-541. (https://doi.org/10.1016/j. beem.2009.05.004)

147 Cerovac V, Monteserin-Garcia J, Rubinfeld H, Buchfelder M, Losa M, Florio T, Paez-Pereda M, Stalla GK \& Theodoropoulou M. The somatostatin analogue octreotide confers sensitivity to rapamycin treatment on pituitary tumor cells. Cancer Research 201070 666-674. (https://doi.org/10.1158/0008-5472.CAN-09-2951)

148 Gorshtein A, Rubinfeld H, Kendler E, Theodoropoulou M, Cerovac V, Stalla GK, Cohen ZR, Hadani M \& Shimon I. Mammalian target of rapamycin inhibitors rapamycin and RAD001 (everolimus) induce anti-proliferative effects in GH-secreting pituitary tumor cells in vitro. Endocrine-Related Cancer 200916 1017-1027. (https://doi. org/10.1677/ERC-08-0269)

149 Zatelli MC, Minoia M, Filieri C, Tagliati F, Buratto M, Ambrosio MR, Lapparelli M, Scanarini M \& Degli Uberti EC. Effect of everolimus on cell viability in nonfunctioning pituitary adenomas. Journal of Clinical Endocrinology and Metabolism 201095 968-976. (https://doi. org/10.1210/jc.2009-1641)

150 Chanal M, Chevallier P, Raverot V, Fonteneau G, Lucia K, Monteserin Garcia JL, Rachwan A, Jouanneau E, Trouillas J, Honnorat J et al. Differential effects of PI3K and dual PI3K/mTOR inhibition in rat prolactin-secreting pituitary tumors. Molecular Cancer Therapeutics 201615 1261-1270. (https://doi.org/10.1158/1535-7163.mct-150891)

151 Lee M, Wiedemann T, Gross C, Leinhäuser I, Roncaroli F, Braren R \& Pellegata NS. Targeting PI3K/mTOR signaling displays potent antitumor efficacy against nonfunctioning pituitary adenomas. Clinical Cancer Research 201521 3204-3215. (https://doi. org/10.1158/1078-0432.CCR-15-0288)

152 Donovan LE, Arnal AV, Wang SH \& Odia Y. Widely metastatic atypical pituitary adenoma with mTOR pathway STK11(F298L) mutation treated with everolimus therapy. CNS Oncology 20165 203-209. (https://doi.org/10.2217/cns-2016-0011)

153 Cooper O, Vlotides G, Fukuoka H, Greene MI \& Melmed S. Expression and function of ErbB receptors and ligands in the pituitary. Endocrine-Related Cancer 201118 R197-R211. (https://doi. org/10.1530/ERC-11-0066)

154 Fukuoka H, Cooper O, Ben-Shlomo A, Mamelak A, Ren SG, Bruyette D \& Melmed S. EGFR as a therapeutic target for human, canine, and mouse ACTH-secreting pituitary adenomas. Journal of Clinical Investigation 2011121 4712-4721. (https://doi.org/10.1172/ JCI60417)

155 Fukuoka H, Cooper O, Mizutani J, Tong Y, Ren SG, Bannykh S \& Melmed S. HER2/ErbB2 receptor signaling in rat and human prolactinoma cells: strategy for targeted prolactinoma therapy. Molecular Endocrinology 201125 92-103. (https://doi.org/10.1210/ me.2010-0353)

156 Vlotides G, Siegel E, Donangelo I, Gutman S, Ren SG \& Melmed S. Rat prolactinoma cell growth regulation by epidermal growth factor receptor ligands. Cancer Research 200868 6377-6386. (https://doi. org/10.1158/0008-5472.CAN-08-0508)

157 Cooper O, Mamelak A, Bannykh S, Carmichael J, Bonert V, Lim S, Cook-Wiens G \& Ben-Shlomo A. Prolactinoma ErbB receptor expression and targeted therapy for aggressive tumors. Endocrine 201446 318-327. (https://doi.org/10.1007/s12020-013-0093-x)

158 Ortiz LD, Syro LV, Scheithauer BW, Ersen A, Uribe H, Fadul CE, Rotondo F, Horvath E \& Kovacs K. Anti-VEGF therapy in pituitary carcinoma. Pituitary 201215 445-449. (https://doi.org/10.1007/ s11102-011-0346-8)

159 Kuyumcu S, Özkan ZG, Sanli Y, Yilmaz E, Mudun A, Adalet I \& Unal S. Physiological and tumoral uptake of (68)Ga-DOTATATE: standardized uptake values and challenges in interpretation. Annals of Nuclear Medicine 201327 538-545. (https://doi.org/10.1007/ s12149-013-0718-4)

160 Xiao J, Zhu Z, Zhong D, Ma W \& Wang R. Improvement in diagnosis of metastatic pituitary carcinoma by 68Ga DOTATATE PET/CT. Clinical Nuclear Medicine 201540 e129-e131. (https://doi. org/10.1097/RLU.0000000000000462)

161 Kwekkeboom DJ, de Herder WW \& Krenning EP. Somatostatin receptor-targeted radionuclide therapy in patients with gastroenteropancreatic neuroendocrine tumors. Endocrinology Metabolism Clinics of North America 201140 173-185, ix. (https://doi. org/10.1016/j.ecl.2010.12.003)

162 Imhof A, Brunner P, Marincek N, Briel M, Schindler C, Rasch H, Mäcke HR, Rochlitz C, Müller-Brand J \& Walter MA. Response, survival, and long-term toxicity after therapy with the radiolabeled somatostatin analogue [90Y-DOTA]-TOC in metastasized neuroendocrine cancers. Journal of Clinical Oncology 201129 2416-2423. (https://doi.org/10.1200/JCO.2010.33.7873)

163 Goglia U, Ferone D, Sidoti M, Spaziante R, Dadati P, Ravetti JL, Villa G, Bodei L, Paganelli G, Minuto F \& Giusti M. Treatment of a pituitary metastasis from a neuroendocrine tumour: case report and literature review. Pituitary 200811 93-102. (https://doi.org/10.1007/ s11102-007-0038-6)

164 Baldari S, Ferrau F, Alafaci C, Herberg A, Granata F, Militano V, Salpietro FM, Trimarchi F \& Cannavo S. First demonstration of the effectiveness of peptide receptor radionuclide therapy (PRRT) with 111In-DTPA-octreotide in a giant PRL-secreting pituitary adenoma resistant to conventional treatment. Pituitary 201215 (Supplement 1) S57-S60. (https://doi.org/10.1007/s11102-011-0373-5)

165 Priola SM, Esposito F, Cannavò S, Conti A, Abbritti RV, Barresi V, Baldari S, Ferraù F, Germanò A, Tomasello F et al. Aggressive pituitary adenomas: the dark side of the moon. World Neurosurgery 201797 140-155. (https://doi.org/10.1016/j.wneu.2016.09.092)

166 Komor J, Reubi JC \& Christ ER. Peptide receptor radionuclide therapy in a patient with disabling non-functioning pituitary adenoma. Pituitary 201417 227-231. (https://doi.org/10.1007/s11102-0130494-0)

167 Maclean J, Aldridge M, Bomanji J, Short S \& Fersht N. Peptide receptor radionuclide therapy for aggressive atypical pituitary adenoma/carcinoma: variable clinical response in preliminary evaluation. Pituitary 201417 530-538. (https://doi.org/10.1007/ s11102-013-0540-y)

168 Waligórska-Stachura J, Gut P, Sawicka-Gutaj N, Liebert W, Gryczyńska M, Baszko-Błaszyk D, Blanco-Gangoo AR \& Ruchała M. Growth hormone-secreting macroadenoma of the pituitary gland successfully treated with the radiolabeled somatostatin analog (90) Y-DOTATATE: case report. Journal of Neurosurgery 2016125 346-349. (https://doi.org/10.3171/2015.6.JNS15363)

169 Kovacs GL, Goth M, Rotondo F, Scheithauer BW, Carlsen E, Saadia A, Hubina E, Kovacs L, Szabolcs I, Nagy P et al. ACTH-secreting Crooke cell carcinoma of the pituitary. European Journal of Clinical Investigation 201343 20-26. (https://doi.org/10.1111/eci.12010)

170 Landman RE, Horwith M, Peterson RE, Khandji AG \& Wardlaw SL. Long-term survival with ACTH-secreting carcinoma of the pituitary: 
a case report and review of the literature. Journal of Clinical Endocrinology and Metabolism 200287 3084-3089. (https://doi. org/10.1210/jcem.87.7.8667)

171 Raverot G, Assie G, Cotton F, Cogne M, Boulin A, Dherbomez M, Bonneville JF \& Massart C. Biological and radiological exploration and management of non-functioning pituitary adenoma. Annales d'Endocrinologie 201576 201-209. (https://doi.org/10.1016/j. ando.2015.04.005)

172 Cannavò S, Venturino M, Curtò L, De Menis E, D'Arrigo C, Tita P, Billeci D \& Trimarchi F. Clinical presentation and outcome of pituitary adenomas in teenagers. Clinical Endocrinology $2003 \mathbf{5 8}$ 519-527. (https://doi.org/10.1046/j.1365-2265.2003.01748.x)

173 Salenave S, Ancelle D, Bahougne T, Raverot G, Kamenický P, Bouligand J, Guiochon-Mantel A, Linglart A, Souchon PF, Nicolino M et al. Macroprolactinomas in children and adolescents: factors associated with the response to treatment in 77 patients. Journal of Clinical Endocrinology and Metabolism 2015100 1177-1186. (https://doi.org/10.1210/jc.2014-3670)

174 Guzel A, Tatli M, Senturk S, Guzel E, Cayli SR \& Sav A. Pituitary carcinoma presenting with multiple metastases: case report. Journal of Child Neurology 200823 1467-1471. (https://doi. org $/ 10.1177 / 0883073808319078$ )

175 Felker J, Patterson B, Wrubel D \& Janss A. Successful treatment of a child with a prolactin secreting macroadenoma with temozolomide. Journal of Pediatric Endocrinology and Metabolism 201629 1413-1415. (https://doi.org/10.1515/jpem-2016-0159)

176 Robenshtok E, Benbassat CA, Hirsch D, Tzvetov G, Cohen ZR, Iraqi HM, Gorshtein A, Toledano Y \& Shimon I. Clinical course and outcome of nonfunctioning pituitary adenomas in the elderly compared with younger age groups. Endocrine Practice 201420 159-164. (https://doi.org/10.4158/EP13182.OR)

177 Kurosaki M, Saeger W \& Lüdecke DK. Pituitary tumors in the elderly. Pathology: Research and Practice 2001197 493-497. (https://doi. org/10.1078/0344-0338-00117)

178 Yunoue S, Tokimura H, Tominaga A, Fujio S, Karki P, Usui S, Kinoshita Y, Habu M, Moinuddin FM, Hirano $\mathrm{H}$ et al. Transsphenoidal surgical treatment of pituitary adenomas in patients aged 80 years or older. Neurosurgical Review 201437 269-276. (https://doi.org/10.1007/s10143-013-0509-3)

179 Minniti G, Esposito V, Piccirilli M, Fratticci A, Santoro A \& JaffrainRea ML. Diagnosis and management of pituitary tumours in the elderly: a review based on personal experience and evidence of literature. European Journal of Endocrinology 2005153 723-735. (https://doi.org/10.1530/eje.1.02030)
180 Liu J, Li C, Xiao Q, Gan C, Chen X, Sun W, Li X, Xu Y, Chen J, Shu K et al. Comparison of pituitary adenomas in elderly and younger adults: clinical characteristics, surgical outcomes, and prognosis. Journal of the American Geriatrics Society 201563 1924-1930. (https://doi.org/10.1111/jgs.13590)

181 Seltzer J, Carmichael JD, Commins D, Liu CS, Omura E, Chang E $\&$ Zada G. Prolactin-secreting pituitary carcinoma with dural metastasis: diagnosis, treatment, and future directions. World Neurosurgery 201691 676.e623-678.e623. (https://doi.org/10.1016/j. wneu.2016.04.112)

182 Grandidge C, Hall A \& Kitchen N. Secreting follicle-stimulating hormone pituitary carcinoma with cervical metastasis. World Neurosurgery 201693 490.e413-496.e413. (https://doi.org/10.1016/j. wneu.2016.05.095)

183 Araujo PB, Vieira Neto L \& Gadelha MR. Pituitary tumor management in pregnancy. Endocrinology Metabolism Clinics of North America 2015 44 181-197. (https://doi.org/10.1016/j.ecl.2014.10.015)

184 Jornayvaz FR, Assie G, Bienvenu-Perrard M, Coste J, Guignat L, Bertherat J, Silvera S, Bertagna X \& Legmann P. Pregnancy does not accelerate corticotroph tumor progression in Nelson's syndrome. Journal of Clinical Endocrinology and Metabolism 201196 E658-E662. (https://doi.org/10.1210/jc.2010-2235)

185 Molitch ME. Endocrinology in pregnancy: management of the pregnant patient with a prolactinoma. European Journal of Endocrinology 2015172 R205-R213. (https://doi.org/10.1530/EJE14-0848)

186 Melmed S, Casanueva FF, Hoffman AR, Kleinberg DL, Montori VM, Schlechte JA, Wass JA \& Society E. Diagnosis and treatment of hyperprolactinemia: an Endocrine Society clinical practice guideline. Journal of Clinical Endocrinology and Metabolism 201196 273-288. (https://doi.org/10.1210/jc.2010-1692)

187 Katznelson L, Laws ER Jr, Melmed S, Molitch ME, Murad MH, Utz A $\&$ Wass JA. Acromegaly: an endocrine society clinical practice guideline. Journal of Clinical Endocrinology and Metabolism 201499 3933-3951. (https://doi.org/10.1210/jc.2014-2700)

188 Nieman LK, Biller BM, Findling JW, Murad MH, Newell-Price J, Savage MO, Tabarin A \& Society E. Treatment of Cushing's syndrome: an endocrine society clinical practice guideline. Journal of Clinical Endocrinology and Metabolism 2015100 2807-2831. (https://doi.org/10.1210/jc.2015-1818)

189 Beck-Peccoz P, Lania A, Beckers A, Chatterjee K \& Wemeau JL. 2013 European thyroid association guidelines for the diagnosis and treatment of thyrotropin-secreting pituitary tumors. European Thyroid Journal 20132 76-82. (https://doi.org/10.1159/000351007)

Received 10 October 2017

Accepted 12 October 2017 